This item was submitted to Loughborough's Research Repository by the author.

Items in Figshare are protected by copyright, with all rights reserved, unless otherwise indicated.

\title{
Nonlinear pricing for stochastic container leasing system
}

PLEASE CITE THE PUBLISHED VERSION

https://doi.org/10.1016/j.trb.2016.03.012

PUBLISHER

(c) Elsevier

VERSION

AM (Accepted Manuscript)

PUBLISHER STATEMENT

This work is made available according to the conditions of the Creative Commons Attribution-NonCommercialNoDerivatives 4.0 International (CC BY-NC-ND 4.0) licence. Full details of this licence are available at: https://creativecommons.org/licenses/by-nc-nd/4.0/

\section{LICENCE}

CC BY-NC-ND 4.0

\section{REPOSITORY RECORD}

Jiao, Wendy, Hong Yan, and King-Wah Pang. 2016. "Nonlinear Pricing for Stochastic Container Leasing System". Loughborough University. https://hdl.handle.net/2134/26457. 


\title{
Nonlinear Pricing for Stochastic Container Leasing System
}

\author{
Wen Jiao*1, Hong Yan ${ }^{1}$, and King-Wah Pang ${ }^{1}$ \\ ${ }^{1}$ Department of Logistics and Maritime Studies, The Hong Kong Polytechnic \\ University, Kowloon, Hong Kong, China
}

April 4, 2016

\begin{abstract}
With the substantial upsurge of container traffic, the container leasing company thrives on the financial benefits and operational flexibility of leasing containers requested by shippers. In practice, container lease pricing problem is different from the consumer product pricing in consideration of the fair value of container, limited customer types and monopolistic supply market. In view of the durability of container and the diversified lease time and quantity, the pricing is a challenging task for the leasing company. This paper examines the monopolist's nonlinear pricing problems in static and dynamic environments. In particular, the leasing company designs and commits a menu of price and hire quantity/time pairs to maximize the expected profit and in turn customers choose hire quantities/time to maximize their surpluses according to their hire preferences. In a static environment, closed-form solutions are obtained for different groups of customers with multiple types subject to capacity constraint. In a dynamic environment, we address two customer types and derive closed-form solutions for the problem of customers with hire time preference. Further, we show that the effect of the capacity constraint increases with time of the planning horizon when customers have the same hire time preference; while in the case with different hire time preferences, the capacity constraint has opposite effects on the low and high type customers. Last, the case of customers with hire quantity preference is discussed. We focus on the lease with alternative given sets of hire time and use dynamic programming to derive the numerical optimal hire time sequence.
\end{abstract}

\footnotetext{
${ }^{*}$ Correspondence to: Wen Jiao (wendy.j@connect.ployu.hk)
} 
Keywords: Container leasing, nonlinear pricing problem, price discrimination, dynamic mechanism design

\section{Introduction}

In the past two decades, global container trade has witnessed a substantial upsurge growing from 28.7 million TEU (Twenty-foot Equivalent Unit)s in 1990 to 161 million TEUs in 2013 (UNCTAD 2014). In contrast to the thriving container trade, the leasing companies' share of world container fleet does not change much, from $43.2 \%$ of 6.4 million in 1990 to $46.2 \%$ of 34.4 million in 2013 (Drewry 2014). The relatively stable share of leasing company in ownership partially reveals the strong demand of shipping companies whose needs are satisfied by lessors flexible services. From the lessor's perspective, the leasing company ${ }^{1}$ could enjoy the economies of scale by the procurement of large numbers of containers, efficient utilization and access to raise capital at a competitive rate in a volatile economy. From the lessee's perspective, renting containers could serve as a financial tool with the following advantages.

- Conserving capital. Instead of purchasing containers, the shipping companies are relieved from the burden of the huge expenditure on containers. It is reasonable especially when the new container price is too high or it is difficult to raise finance for container investment such as in the recession year of 2009. This reserves lessee's limited borrowing capacity for more profitable investments, such as infrastructure depots and IT facilities.

- Providing a better fiscal picture. The lease is usually qualified as pretax expense and considered as 'off-balance-sheet financing'. The monthly payment appears on the balance sheet as expense rather than long term debt.

- Avoiding risk. With fixed and predictable payment on container lease, the shipper is protected from inflation.

Besides the financial benefits, the operational advantages of renting containers to supplement their own fleet are as follows.

\footnotetext{
${ }^{1}$ For variety, we use lessor, leasing company, monopolist interchangeably without confusion.
} 
- Quick response to demand changes. Some shipping lines have extremely high imbalance container flows owing to imbalance of trade volume between continents. For instance, in 2013, the container moving from Asia to North America (13.8 Million TEUs) is about twice of that from North America to Asia (7.4 million TEUs). The imbalance between Asia and Europe is even bigger with ratio 14.1:6.4 (UNCTAD 2014). The consequence of such a imbalance cargo flow is the higher cost per TEU for these routes, which is a difficult task in capacity management to the shipping companies. In addition, the trade volume and the demand of containers are high during peak seasons such as Christmas. After holidays, the demand falls back to a low level. Therefore, it is reasonable to rent containers for fluctuating seasonal demand or imbalance cargo routes.

- High flexibility. It is convenient for a shipper to pick up/drop off containers at the nearest depot and select the most suitable lease contracts to satisfy their needs. When the lease period expires, the lessee could return, purchase, re-lease or replace the leased containers.

- Cost Saving. The shippers receive carefully designed services with high quality control, unique depot selection, professional repair and the disposal of used containers. The leasing service reduces costs such as overhead cost, maintenance cost, finance cost and administrative cost.

The container lease contracts can be divided into two categories: master lease and term lease. Master lease is also referred to a full service lease. Both parties agree on a master contract: the shipper has the right to pick up/drop off container at his convenience and changes the number of leased containers under the basic terms. The lessor is responsible for repositioning the empty containers and the maintenance and repair. The term lease has fixed lease duration including short and long terms, ranging from a single-trip lease up to eight years rent. Unlike a master lease, the lessee is responsible for the maintenance and repair of containers.

In the container leasing industry, pricing is a very challenging factor for a leasing company. The main characteristics of container lease are the fair value of container, stable and limited customer types and monopolistic supply market. (1)

Fair value of container. A container is labeled as an industrial product and durable good. Its value is much higher than those of daily commodities but lower than those of precision equipment. The average ex-factory price for newbuild 
TEU and resale price for used TEU in 2013 are US $\$ 2150$ and US\$1260 respectively (Drewry 2014). (2) Limited customer types. The target customers of container lease are big shipping companies with long-term contractual relationship. There are limited discrete customer types. In the changing lease market, each customer (shipper) requests large numbers of container with diverse hire time (from one month to five years) depending on his own demand. The varied lease time and quantities of different customer types in container lease meet the requirement for second-degree price discrimination mechanism (different prices for distinct quantities). In other words, the leasing company should pay attention to the characteristics of each customer in the price determination process which is the essence of the nonlinear pricing problem. By contrast, in service pricing, the target customers are individual customers who usually demand for one unit without any contractual relationship and have wide variety of customer types. (3) Monopolistic supply market. The container leasing industry has been dominated by a small groups of influential companies about two decades. The top ten companies control $87.5 \%$ of the entire lease fleet. The top tier is headed by long-standing number one, Taxtainer Group. Its fleet is about $40 \%$ bigger than its nearest competitor (Drewry, 2014). This is the reason why the monopolist supply market is studied in our paper. In practice, the lease rate determined by a leasing company is usually based on the past leasing experience. Thus it is necessary to have a scientific method assisting the leasing company on the pricing determination process.

Based on the main features of container lease, the price and discount affect customers' intention to deal, hire time and quantity. The more favorable price offered to longer hire time and larger lease quantity incurs an opportunity cost, resulting in inadequate capacity of containers that affects the lessor from gaining future profit from other customers. On the other hand, higher price deters consumers' interest to rent and cause more idle capacity. There is clearly a need for identifying the hire discount and time discount in the lease system given a capacity constraint. Thus, in this paper, we investigate the static and dynamic rental revenue management problem considering several situations (short-term lease and long-term lease) in practice. The company commits a price menu with hire quantity (time) to maximize the expected profit and in turn customers choose their hire quantities/time to maximize their surpluses based on their hire preferences. In Section 3, the company allocates the capacity once in a static environment. Closed 
form solutions are obtained for different groups of customers subject to capacity constraint. In Section 4, the company allocates the finite capacity repeatedly in the planning horizon. For the case of customers with hire time preference in Section 4.1, closed-form solutions are derived and the effect of capacity constraint are discussed. For the case of customers with hire quantity preference in Section 4.2, we adopt dynamic programming to acquire the numerical optimal solution and discuss the effect of parameters on the optimal solution.

\section{Literature Review}

Our work is built on three streams of literature: study about rental service system, static and dynamic mechanism design.

There is a burgeoning scholarly literature on the rental systems. Recent related study about rental systems mostly concentrate on the following major problems, empty container reposition problem in some regions with imbalance inbound and outbound traffic (Song and Dong, 2012, Bell et al., 2013), capacity rationing problem for different customer types (Savin et al., 2005, Papier and Thonemann, 2010). Besides, Gans and Savin (2007) study the rental/service revenue management and capacity allocation problem as queuing model. In queuing model, once the price is accepted by the customer, the rental duration is a given parameter following exponential distribution rather than a specific rental time selected by each consumer. Dobbs (1995) examines a monopolist's inter-temporal nonlinear pricing problem with unit/excess capacity where customers arrive randomly and choose their hire time. Polynomial function is utilized to represent the price schedule. The optimal pricing policy is sensitive to customer arrival frequency but insensitive to changes in time discount rate. Dobbs captures the main feature of rental system - customers have the option of selecting the hire time. In his model, same type customers select the same hire time which is history independent in the infinite horizon. To the best of our knowledge, there is no paper analyzing the pricing and capacity rationing problem in the context of container leasing industry.

Various study about static mechanism design problem addresses the dynamics between customer information and the company's pricing schedule. This line of research starts with the seminal work of Mussa and Rosen (1978). They explore a monopolist's price-quality schedule allocating quality-differentiated goods to customers under self-selection constraint. In Myerson (1981), his contribution to the 
literature on unidimensional continuous customer types is the identification of the optimal auction structure to attain the criterion (e.g. social welfare maximization, customer purchasing cost minimization). Maskin and Riley (1984) demonstrate that under a separability assumption, the seller's optimal price-quantity schedule has the quantity-discount structure. Based on these pioneer works, the mechanism design theory of pricing has been applied to information goods (Sundararajan, 2004), multiproduct (Armstrong, 1996), parking slot assignment (Zou et al., 2015) and transportation service procurement (Huang and $\mathrm{Xu}, 2013$ ).

The dynamic mechanism design literature can be classified by two strands of literature according to the nature of dynamics. One strand of literature primarily focuses on the setting that a dynamic population arrives over time with fixed preference and the allocation for each customer is determined only once (Pai and Vohra, 2013, Zou et al., 2015). The other strand considers a fixed population whose preference evolves over time and allocation for each customer is determined repeatedly. Our paper is more relevant to this strand of literature. Battaglini (2005) investigates the optimal contract between a monopolist and a customer whose valuation follows a Markov process in an infinite horizon. The optimal contract is non-stationary and converges to efficient contract over time. The differences between our paper and Battaglini's work are that we consider multiple customers, one more dimension of product characteristics (hire time) and capacity constraint. Athey and Segal (2013), Kakade et al. (2013), Pavan et al. (2014) study the social welfare maximization and incentive compatible mechanisms in dynamic environments. Athey and Segal (2013) construct a budge-balanced mechanism in general dynamic environments. Kakade et al. (2013) explore the optimal mechanism design in separable environments with dynamic private information. They employ a relaxation method to first find an allocation rule in the relaxed environment and then determine the allocation rule is ex post incentive compatible under the restriction that each agent needs to report his entire type history in each period. Pavan et al. (2014) adopt the first-order approach to study mechanism design in dynamic quasilinear environment which each agent has a dynamic unidimensional private information. Battaglini and Lamba (2014) examine a dynamic principalagent model in which the agent's types are serially correlated and follow a Markov process. They show a dynamic envelope formula considering only local incentive compatibility constraints but the formula fails to characterize the optimal dynamic contract in general dynamic environments. So they present the suboptimal 
monotonic contracts which works well in complex environments. Bergemann and Said (2011) provide a detailed review of dynamic mechanism design. However, the above studies on dynamic mechanism design assume that the characteristic of product only has the quantity dimension or quality dimension under unit demand assumption, in our paper, we extend the problem with consideration of two dimensions, hire quantity and hire time. We believe that this is the first paper to consider two dimensional features of product in a dynamic environment.

\section{Static Nonlinear Pricing Problem}

In this section, we discuss an atemporal monopolist nonlinear pricing problem where the capacity is rationed once. In the next section, we study the intertemporal nonlinear pricing problem where the capacity is allocated repeatedly in the finite horizon.

In this paper, the cases we focus on that the lessee has hire quantity/time preference are motivated by industry operations. The short term lease is also called spot lease or trip lease. The lease is provided on a short term period (month, quarter) or specific route basis with predetermined delivery schedule (Theofanis and Boile, 2009, Drewry, 2014). The liner ship carrier announces the ports of call of a specific route with specific estimated time of arrival and departure. This information is usually known in advance and considered constant. The shippers will then make reservation to occupy certain capacity (in TEUs) of a voyage with specific origin-destination pair. They will consider rent the containers from the leasing company for this specific shipment if their own containers is insufficient. If the route of the liner shipping service has only one origin-destination port, the hire time of all customers are considered the same; if there are multiple ports of call, this leads to the situation that customers may have different hire time preferences. The leasing company enters into long-term leases for a fixed term normally ranging from three to eight years, with five-year term leases being most common (Textainer, 2014). In the long term lease, the shipper enquires their strategic partners or open calls for tenders to choose the alternative lessor. The final winner may be a sole bidder or two/three bidders who share the contract. Under the agreement of preferred hire time (quantity), the hire quantity (time) is decided based on the price offered by leasing companies.

Besides the industry practice, the existing literature about empty container al- 
location and reposition also supports the hire quantity or hire preference assumption. Cheung and Chen (1998), Shu and Song (2013) study the empty container reposition problem. Based on the fixed ship schedules and voyages, the line shipper knows that the time of departure and arrival for each vessel at any port and then determines the number of container repositioned/owned and the number of leased containers. Bell et al. (2013) discusses a cost-based container assignment model which the shipper has hire quantity preference and then decides the leg flow and dwell time to minimize the total cost.

\subsection{One group of customers}

The monopolist (leasing company) has $C$ units of container available to rent by $M$ customers at one time. In this subsection, we assume that all $M$ customers have the same hire time $d$. This assumption is reasonable as in the long-term lease contract five year is the most common hire time. A customer usually has a preferred hire time and then choose the hire quantity depending on the posted price. Further, in view of the sufficient long hire time, the market would be quite different from now when the containers are returned. Hence, it is more sensible to model this pricing problem in the long-term lease contract as an atemporal nonlinear pricing problem. The company determines a vector of quantity and price pairs associated with each customer type to maximize the expected profit and each customer selects the hire quantity and price pair designed for his type.

The $M$ customers are classified into $N$ types, where $M<N$. A customer's valuation refers to the benefit that a customer obtains from the leasing service. A customer's valuation, $\bar{\theta}_{i} \in \bar{\Theta}$, is private information and drawn from a known iid probability mass function $f\left(\bar{\theta}_{i}\right)$ and cumulative distribution function $F\left(\bar{\theta}_{i}\right)$, shortened as $f_{i}$ and $F_{i}$ respectively. $\bar{\Theta}=\left\{\bar{\theta}_{1}, \bar{\theta}_{2}, \ldots, \bar{\theta}_{N}\right\}$ is a finite set with $\bar{\theta}_{i}=i \psi$ for some $\psi>0$. Assume that $f_{i}$ and $F_{i}$ satisfy the monotone hazard rate condition, if $j>i$ then $\frac{1-F_{j}}{f_{j}}>\frac{1-F_{i}}{f_{i}}$. This assumption is quite usual in literature (Anderson and Dana Jr, 2009, Armstrong, 1996, Myerson, 1981). A customer rents $q_{i}$ units of container for hire time $d_{i}$ enjoys utility $U\left(\bar{\theta}_{i}, d_{i}, q_{i}\right)=\bar{\theta}_{i} d_{i} q_{i}-\frac{1}{2}\left(d_{i}^{2}+q_{i}^{2}\right)$. The quadratic utility function follows the tradition of the literature (Rochet and Stole, 2003, Sundararajan, 2004, Wilson, 1993). Let $Y$ be the fixed lease contract setup cost. The operating cost per time per unit for the leasing company is $a$ and $a<\psi$. The unit benefit $\psi$ obtained by the customer could not lower than the operating cost per unit $a$ of the leasing company. The direct operating expense 
includes storage, handling, maintenance, and reposition. Such operating cost is a component of the objective function of these empty container reposition articles (Bell et al., 2013, Cheung and Chen, 1998, Song and Dong, 2012), which is linear in the number of containers and the duration of the lease contract. The adoption of linear cost function is just to simplify exposition, and it is easy to extend to some other forms of cost function. In this section with same hire time $d$, let $\theta_{i}=\bar{\theta}_{i} d$ and $U\left(\bar{\theta}_{i}, d_{i}, q_{i}\right)$ becomes to $U\left(\theta_{i}, q_{i}\right)=\theta_{i} q_{i}-\frac{1}{2}\left(d^{2}+q_{i}^{2}\right)$.

\section{The Company's Problem}

The objective of the leasing company is to maximize the expected profit with finite capacity. In the direct revelation mechanism, the leasing company first announces and commits a menu of quantity $q_{i}$ and price $P_{i}$ pairs for $1 \leq i \leq$ $N$, shortened as $\{Q, P\}$. When a customer arrives at the leasing company, the customer reports a type $i$ based on the announced menu $\{Q, P\}$ to maximize the surplus $U\left(\theta_{i}, q_{i}\right)-P_{i}$. The customer receives $q_{i}$ units of container and issues the payment $P_{i}$.

There are some constraints in which the direct revelation mechanism must satisfy.

Incentive Compatibility $\left(I C_{i j}\right)$ Constraint. Each customer reports his type $i$ truthfully and selects the quantity and price pair $\left\{q_{i}, P_{i}\right\}$ offered to his type. Customer has no incentive to deviate from his type $i$ as the consumer surplus of reporting type $i$ is greater than that reporting other types $j(j \neq i)$. Thus, truthfulness is the best strategy to maximize his own consumer surplus.

$$
U\left(\theta_{i}, q_{i}\right)-P_{i} \geq U\left(\theta_{i}, q_{j}\right)-P_{j} \quad \forall i \text { and } j \text { where } j \neq i
$$

Refer $I C_{i, i+1}$ to the upward $I C$ constraint and $I C_{i, i-1}$ to the downward $I C$ constraint.

Individual Rationality $\left(I R_{i}\right)$ Constraint. Each customer only rents the containers if he has nonnegative consumer surplus.

$$
U\left(\theta_{i}, q_{i}\right)-P_{i} \geq 0 \quad \forall i
$$

Due to the $I R_{i}$ constraint, there exists some customers obtaining positive consumer surpluses, meanwhile some types of customers are priced out of the market. There exists a type $j$ such that $q_{j}=0$ which divides all customers into two categories, for customers with type $k \leq j, q_{k}=0$; otherwise, for $j<k \leq N, q_{k}>0$. In other words, the types of customers who belonged to $[1, j]$ fail to accept the 
price and leave the company; and the types of customers who belonged to $(j, N]$ hire a positive quantity with nonnegative consumer surplus.

Capacity Constraint $(C C)$. The total units of container allocated cannot exceed the available capacity.

$$
M \sum_{i} f_{i} q_{i} \leq C
$$

The expected profit of the leasing company is the expected revenue minus the fixed setup cost and the operating cost. The atemporal nonlinear pricing problem is written as follows.

$$
\begin{aligned}
& \Pi(Q, P)=\max _{\{Q, P\}} M \sum_{i} f_{i}\left(P_{i}-Y-a d q_{i}\right) \\
& \text { s.t. } I C_{i j}, I R_{i}, C C \quad \forall i, j \in[1, \cdots, N]
\end{aligned}
$$

Lemma 3.1. If a mechanism $\{Q, P\}$ is implementable, then $q_{i} \geq q_{j}$ for any $1 \leq j<i \leq N$.

Proof. Suppose that $q_{i}<q_{j}$ for $i>j$. From $I C_{i, j}$ and $I C_{j, i}$ constraints, we have

$$
\begin{array}{ll}
I C_{i, j} & U\left(\theta_{i}, q_{i}\right)-P_{i} \geq U\left(\theta_{i}, q_{j}\right)-P_{j}, \\
I C_{j, i} & U\left(\theta_{j}, q_{j}\right)-P_{j} \geq U\left(\theta_{j}, q_{i}\right)-P_{i} .
\end{array}
$$

The above two inequalities imply that

$$
\theta_{i}\left(q_{j}-q_{i}\right) \leq P_{j}-P_{i}+\frac{1}{2}\left(q_{j}^{2}-q_{i}^{2}\right) \leq \theta_{j}\left(q_{j}-q_{i}\right) .
$$

According to assumption $\theta_{i}>\theta_{j}$ and $q_{j}>q_{i}$, we obtain that $\theta_{i}\left(q_{j}-q_{i}\right)>\theta_{j}\left(q_{j}-q_{i}\right)$, yielding a contradiction.

Denote the consumer surplus of type $i$ as $S\left(\theta_{i}\right)=U\left(\theta_{i}, q_{i}\right)-P_{i}$.

Lemma 3.2. If a mechanism $\{Q, P\}$ is implementable, then for all customer types $i$,

$$
\begin{aligned}
& S\left(\theta_{i}\right) \geq S\left(\theta_{1}\right)+\psi d \sum_{k=1}^{i-1} q_{k} \\
& S\left(\theta_{i}\right) \leq S\left(\theta_{1}\right)+\psi d \sum_{k=2}^{i} q_{k}
\end{aligned}
$$


Proof. From $I C_{i, i-1}$, we have

$$
S\left(\theta_{i}\right)=U\left(\theta_{i}, q_{i}\right)-P_{i} \geq U\left(\theta_{i}, q_{i-1}\right)-P_{i-1}
$$

And the right side of the above equation can be rewritten as

$$
\begin{aligned}
& U\left(\theta_{i}, q_{i-1}\right)-P_{i-1} \\
= & U\left(\theta_{i-1}, q_{i-1}\right)-P_{i-1}+U\left(\theta_{i}, q_{i-1}\right)-U\left(\theta_{i-1}, q_{i-1}\right) \\
= & S\left(\theta_{i-1}\right)+\psi d q_{i-1} .
\end{aligned}
$$

Accordingly, we have $S\left(\theta_{i}\right) \geq S\left(\theta_{i-1}\right)+\psi d q_{i-1}$. Summing up the constraints from $I C_{i, i-1}$ to $I C_{2,1}$, we get

$$
S\left(\theta_{i}\right) \geq S\left(\theta_{1}\right)+\psi d \sum_{k=1}^{i-1} q_{k} .
$$

Similarly, summing up the constraints from $I C_{i-1, i}$ to $I C_{1,2}$ and we obtain (6).

Lemma 3.3. If the adjacent downward (upward) IC constraint binds, then the corresponding upward (downward) IC constraint is satisfied.

Proof. If $I C_{i, i-1}$ binds, $U\left(\theta_{i}, q_{i}\right)-U\left(\theta_{i}, q_{i-1}\right)=P_{i}-P_{i-1}$. Recall that $U\left(\theta_{i}, q_{i}\right)=$ $\theta_{i} q_{i}-\frac{1}{2}\left(d^{2}+q_{i}^{2}\right)$, then

$$
\begin{array}{r}
\theta_{i-1}\left(q_{i}-q_{i-1}\right)+\frac{1}{2}\left(q_{i-1}^{2}-q_{i}^{2}\right)=U\left(\theta_{i-1}, q_{i}\right)-U\left(\theta_{i-1}, q_{i-1}\right) \\
<U\left(\theta_{i}, q_{i}\right)-U\left(\theta_{i}, q_{i-1}\right)=\theta_{i}\left(q_{i}-q_{i-1}\right)+\frac{1}{2}\left(q_{i-1}^{2}-q_{i}^{2}\right)
\end{array}
$$

It follows that $U\left(\theta_{i-1}, q_{i}\right)-U\left(\theta_{i-1}, q_{i-1}\right)<P_{i}-P_{i-1}$. The upward $I C_{i-1, i}$ constraint is satisfied.

The atemporal nonlinear pricing problem with capacity constraint can be transformed to a standard static nonlinear pricing problem using the Lagrange multiplier approach. Based on the above lemmas, we could consider the relaxed problem which the adjacent downward $I C_{i, i-1}$ and $I R_{1}$ constraints bind. The binding constraint $I R_{1}$ means that $S\left(\theta_{1}\right)=0$ and the binding constraints $I C_{i, i-1}$ indicates that $S\left(\theta_{i}\right)=\psi d \sum_{k=1}^{i-1} q_{k}$. As a result, the optimal menu of prices can be derived from the binding downward $I C$ constraints. Replace $P_{i}=U\left(\theta_{i}, q_{i}\right)-S\left(\theta_{i}\right)$ 
and reformulate the problem (4) as

$$
\begin{gathered}
\Pi(Q, \lambda)=\max _{\{Q, \lambda\}} M \sum_{i} f_{i}\left[U\left(\theta_{i}, q_{i}\right)-S\left(\theta_{i}\right)-Y-a d q_{i}\right]+\lambda\left(C-M \sum_{i} f_{i} q_{i}\right) \\
\text { s.t. } \quad S\left(\theta_{1}\right)=0 \quad I R_{1} \\
\qquad S\left(\theta_{i}\right)=\psi d \sum_{k=1}^{i-1} q_{k} \quad I C_{i, i-1} \text { for } 2 \leq i \leq N
\end{gathered}
$$

Theorem 3.1. The optimal allocation policy of atemporal nonlinear pricing problem is characterized as follows. Let $w_{i}=i-\frac{1-F_{i}}{f_{i}}$ and $i^{*}=\arg \min \left\{i \mid w_{i}>\frac{a}{\psi}\right\}$.

- If $\left(i^{*}-\frac{a}{\psi}\right)\left(1-F_{i^{*}-1}\right) \leq \frac{C}{M d \psi}$, then the capacity constraint is not binding. For $i<i^{*}$, the optimal quantity $q_{i}$ is $0 ;$ for $i^{*} \leq i \leq N, q_{i}=d \psi w_{i}-a d$.

- If $\left(i^{*}-\frac{a}{\psi}\right)\left(1-F_{i^{*}-1}\right)>\frac{C}{M d \psi}$, then the capacity constraint is binding. For $i<i^{*}$, the optimal quantity $q_{i}$ is 0 ; for $i^{*} \leq i \leq N, q_{i}=d \psi w_{i}-$ ad $-\lambda$ where $\lambda=d \psi i^{*}-a d-\frac{C}{M\left(1-F_{i^{*}-1}\right)}$.

Proof. (i) When the capacity constraint is not binding, then $\lambda=0$ and the problem becomes a standard nonlinear pricing problem. Take the derivative of (7) w.r.t $\theta_{i}$, we can get

$$
\begin{array}{r}
f_{i}\left(i d \psi-a d-q_{i}-d \psi \frac{1-F_{i}}{f_{i}}\right)=0, \\
q_{i}=d \psi w_{i}-a d .
\end{array}
$$

For $i<i^{*}, q_{i}=0$; otherwise, $q_{i}=d \psi w_{i}-a d$. Since capacity constraint is not binding, from $M \sum_{i=i^{*}}^{N} f_{i} q_{i} \leq C$, we have $\left(i^{*}-\frac{a}{\psi}\right)\left(1-F_{i^{*}-1}\right) \leq \frac{C}{M d \psi}$.

(ii) When the capacity constraint is binding, using the Lagrange multiplier approach, (7) can be rewritten as

$$
\begin{gathered}
\Pi(Q, \lambda)=\max _{\{Q, \lambda\}} M \sum_{i} f_{i}\left[\theta_{i} q_{i}-\frac{1}{2}\left(d^{2}+q_{i}^{2}\right)-S\left(\theta_{i}\right)-Y-a d q_{i}-\lambda q_{i}\right]+\lambda C \\
\text { s.t. } I R_{1}, I C_{i, i-1} \quad \text { for } 2 \leq i \leq N
\end{gathered}
$$

The pointwise maximization solution is derived from the derivative about $\theta_{i}$ combining with the binding capacity constraint.

$$
\left\{\begin{array} { l } 
{ f _ { i } ( i d \psi - a d - q _ { i } - d \psi \frac { 1 - F _ { i } } { f _ { i } } - \lambda ) = 0 , } \\
{ M \sum _ { i = i ^ { * } } ^ { N } f _ { i } q _ { i } = C }
\end{array} \Rightarrow \left\{\begin{array}{l}
q_{i}=d \psi w_{i}-a d-\lambda \\
\lambda=d \psi i^{*}-a d-\frac{C}{M\left(1-F_{i^{*}-1}\right)}
\end{array}\right.\right.
$$

The optimal allocation policy corresponding to the binding status of capacity constraint is derived. 
Remark. The leasing company provides different rental contracts based on the type of customers. The total number of customers who receive the lease contract is $M\left(1-F_{i^{*}-1}\right)$.

\subsection{Two different groups of customers}

In this subsection, we consider the case that the $M$ customers are classified into two groups: one group of customers has hire time preference, denoted by Group $I$; another group of customers has hire quantity preference, denoted by Group $J$. Let $\bar{d}_{i}$ be the preferred hire time in Group $I, \bar{d}_{i} \leq \bar{d}_{i+1}(i \in I)$ and $\bar{q}_{j}$ is the preferred hire quantity in Group $J, \bar{q}_{j} \leq \bar{q}_{j+1}(j \in J)$. Assume that each group still has $N$ types. A customer's valuation in Group $I$ is $\theta_{i}^{I}=i \bar{d}_{i} \psi$ and in Group $J$ is $\theta_{j}^{J}=j \bar{q}_{j} \xi$ for $1 \leq i, j \leq N, \psi>0$ and $\xi>0$. The other assumptions are the same as those stated in Section 3.1. The atemporal nonlinear pricing problem with two different groups of customers can be formulated as

$$
\begin{array}{cll}
\max _{\left\{Q_{I}, P_{I}, D_{J}, P_{J}\right\}} & M\left[\sum_{i} f_{i}\left(P_{i}-Y-a \bar{d}_{i} q_{i}\right)+\sum_{j} f_{j}\left(P_{j}-Y-a \bar{q}_{j} d_{j}\right)\right] \\
\text { s.t. } & U\left(\theta_{i}^{I}, q_{i}\right)-P_{i} \geq U\left(\theta_{i}^{I}, q_{i^{\prime}}\right)-P_{i^{\prime}} & I C_{i, i^{\prime}}^{I} \\
& U\left(\theta_{j}^{J}, d_{j}\right)-P_{j} \geq U\left(\theta_{j}^{J}, d_{j^{\prime}}\right)-P_{j^{\prime}} & I C_{j, j^{\prime}}^{J} \\
U\left(\theta_{i}^{I}, q_{i}\right)-P_{i} \geq 0, U\left(\theta_{j}^{J}, d_{j}\right)-P_{j} \geq 0 & I R_{i}^{I}, I R_{j}^{J} \\
M\left[\sum_{i} f_{i} q_{i}+\sum_{j} f_{j} \bar{q}_{j} \mathbf{1}\left(d_{j}>0\right)\right] \leq C & C C \\
\forall i, i^{\prime} \in I, \forall j, j^{\prime} \in J &
\end{array}
$$

The first two constraints are incentive compatible constraints for both groups. The next two constraints are individual rationality constraints. The last is the capacity constraint, and $\mathbf{1}(\cdot)$ is an indicator function. The inequality (5) in Lemma 3.2 becomes to

$$
\begin{aligned}
& S\left(\theta_{i}^{I}\right) \geq S\left(\theta_{1}^{I}\right)+\frac{1}{2}\left(\bar{d}_{1}^{2}-\bar{d}_{i}^{2}\right)+\psi \sum_{k=1}^{i-1} q_{k}\left[(k+1) \bar{d}_{k+1}-k \bar{d}_{k}\right] \\
& S\left(\theta_{j}^{J}\right) \geq S\left(\theta_{1}^{J}\right)+\frac{1}{2}\left(\bar{q}_{1}^{2}-\bar{q}_{i}^{2}\right)+\xi \sum_{k=1}^{j-1} d_{k}\left[(k+1) \bar{q}_{k+1}-k \overline{q_{k}}\right] .
\end{aligned}
$$

To solve this problem, we can still use Lagrange multiplier approach to obtain the optimal solution. 
Theorem 3.2. The optimal allocation policy of atemporal nonlinear pricing problem with two different groups of customers is characterized as follows. The superscripts $s$ and $b$ signify the slack and binding status of the capacity constraint.

- When the capacity constraint is not binding, the optimal allocation policy is that for Group $I, q_{i}^{s}=\left\{i \bar{d}_{i} \psi-a \bar{d}_{i}-\left[(i+1) \bar{d}_{i+1}-i \bar{d}_{i}\right] \frac{1-F_{i}}{f_{i}} \psi\right\}^{+} ;$for Group $J, d_{j}^{s}=\left\{j \bar{q}_{j} \xi-a \bar{q}_{j}-\left[(j+1) \bar{q}_{j+1}-j \bar{q}_{j}\right] \frac{1-F_{j}}{f_{i}} \xi\right\}^{+}$.

- When the capacity constraint is binding, the optimal allocation policy is that for Group I, $q_{i}^{b}=\left\{i \bar{d}_{i} \psi-a \bar{d}_{i}-\left[(i+1) \bar{d}_{i+1}-i \bar{d}_{i}\right] \frac{1-F_{i}}{f_{i}} \psi\right\}^{+}-\lambda$ where $\lambda=$ $\frac{1}{1-F_{i^{*}-1}}\left(\sum_{i \geq i^{*}} f_{i} q_{i}^{s}+\sum_{j \geq j^{*}} f_{j} \bar{q}_{j}-\frac{C}{M}\right)$ and $i^{*}=\arg \min \left\{i \mid q_{i}^{s} \geq 0\right\}, j^{*}=$ $\arg \min \left\{i \mid d_{j}^{s} \geq 0\right\}$; for Group $J, d_{j}^{b}=d_{j}^{s}$.

Proof. The proof is similar to the proof of Theorem 3.1, thus the proof is omitted.

For Group I, when customers have the same preferred hire time, the optimal allocation policy reduces to the optimal policy in Theorem 3.1 except with different $\lambda$ values. The capacity constraint only binds the optimal hire quantity $q_{i}^{b}$ of Group $I$, but not the optimal hire time $d_{j}$ of Group $J$ owing to the fact that customers in this group have preferred hire quantities.

\section{Dynamic Nonlinear Pricing Problem}

In this section, we discuss the monopolist's nonlinear pricing problem in a dynamic environment. In particular, the monopolist determines a menu of quantity (time) and price pairs to maximize the expected profit in discrete-time and finite horizon setting. To better capture the characteristics of the two different groups of customers, we explore the nonlinear pricing problem for customers with preferred hire time and preferred hire quantity separately. In the container lease, the target customers are big shipping companies with long-term contractual relationship. There are limited discrete customer types. Unlike in retail/service pricing, the target customers are individual customers who usually demand for one unit of product without any contractual relationship and have wide variety of customer types. Thus, we first categorize customers by hire preference and then classify customers according to the hire quantity or hire time. Two customer types are used as a start to show the structure of the optimal pricing policy. Suppose that there are two customer types in each group, the low type $L$ and the high type $H$. 


\subsection{Hire time preference}

In this subsection, we describe the situation of a trip lease contract in the short term lease category. Denote the preferred hire time of two customer types by $\bar{d}_{H}$ and $\bar{d}_{L}$. Corresponding to the different situations in practice, we first study the case that $\bar{d}_{H}=\bar{d}_{L}$ and then discuss the case when $\bar{d}_{H}>\bar{d}_{L}$. Let $\theta_{i}=\bar{\theta}_{i} \bar{d}_{i}$ and $\bar{\theta}_{i}>a$.

\subsubsection{Same hire time preference $\left(\bar{d}_{H}=\bar{d}_{L}=d\right)$}

As the $M$ customers of the leasing company have the same hire time preference $d$, there are equidistant time points in finite horizon, $\left\{0=t_{0}, t_{1}, \cdots, t_{K}, t_{K+1}=\right.$ $T\}$, where $t_{k}=k d$ and $t_{K}$ is the last pricing decision point. In a finite period setting, customer type is affected by the shipper's demand and fleet capacity, world trade and economic conditions, the price of new and used containers, shifting trend of cargo traffic and fluctuation in interest rates and currency exchange rates. The above factors directly or indirectly affect the customer type at the leasing time. Therefore, we model the customer valuation as stochastic variable. At time $t_{0}$, the company has a prior information about the proportion of customers being classified into the low and high type, $f_{L}$ and $f_{H}$. The customer type evolves over time according to a Markov process. Let $f_{i j}$ be the probability that a type $i$ customer at time point $t_{k}$ becomes a type $j$ customer at time point $t_{k+1}$ for any $t_{k}$, where $i, j \in\{L, H\}$. The probability $f_{i j}$ is independent of the time point. Moreover, assume that customer types are positively correlated, $f_{H H}-f_{H L}>0$ and $f_{L L}-f_{L H}>0 . \boldsymbol{H}_{k}$ is the set of all possible history up to time $t_{k}$. $h_{k}^{z}$ is the public history up to time point $t_{k}$ and the customer type at $t_{k-1}$ is $z(z \in\{L, H\})$, $h_{k}^{z}:=\left\{h_{k-1}, z\right\}$ and $h_{0}:=\emptyset . h_{k}$ stands for the general history up to time point $t_{k}$. Let $f\left(h_{k}\right)$ be the probability of history $h_{k}$.

At each time point $t_{k}$, the sequence of events is listed as follows: (1) if $k \geq 1$, contracted customers return the rented containers; (2) based on the public history $h_{k}$, the leasing company designs and commits a menu of quantity and price pairs $\{Q, P\}=\left\{q_{i}\left(h_{k}\right), P_{i}\left(h_{k}\right)\right\}$ to maximize the expected profit with time discount factor $\delta$; (3) each customer reports his type to maximize his expected consumer surplus, receives the corresponding quantity of his type and settles the payment.

Let $S\left(\theta_{i} \mid h_{k}\right)$ be a customer's expected surplus with type $i$ up to history $h_{k}$, $S\left(\theta_{i} \mid h_{k}\right)=U\left(\theta_{i}, q_{i}\left(h_{k}\right)\right)-P_{i}\left(h_{k}\right)+\delta^{d} \sum_{j \in\{L, H\}} f_{i j} S\left(\theta_{j} \mid h_{k+1}^{i}\right)$. For notational brevity, 
we denote $q_{i}\left(h_{0}\right):=q_{i}, S\left(\theta_{i} \mid h_{0}\right):=S\left(\theta_{i}\right)$.

Incentive Compatibility $\left(I C_{i j}\left(h_{k}\right)\right)$ Constraint. In a dynamic environment, the incentive compatibility constraint for the high type and history $h_{k}(k=0, \cdots, K)$ can be written as

$$
\begin{array}{r}
U\left(\theta_{H}, q_{H}\left(h_{k}\right)\right)-P_{H}\left(h_{k}\right)+\delta^{d} \sum_{j} f_{H j} S\left(\theta_{j} \mid h_{k+1}^{H}\right) \geq \\
U\left(\theta_{H}, q_{L}\left(h_{k}\right)\right)-P_{L}\left(h_{k}\right)+\delta^{d} \sum_{j} f_{H j} S\left(\theta_{j} \mid h_{k+1}^{L}\right)
\end{array}
$$

Simplify the above inequality, it becomes

$$
S\left(\theta_{H} \mid h_{k}\right) \geq S\left(\theta_{L} \mid h_{k}\right)+\Delta \theta q_{L}\left(h_{k}\right)+\delta^{d} \sum_{j}\left(f_{H j}-f_{L j}\right) S\left(\theta_{j} \mid h_{k+1}^{L}\right)
$$

where $\Delta \theta=\theta_{H}-\theta_{L}=\left(\bar{\theta}_{H}-\bar{\theta}_{L}\right) d$.

Individual Rationality $\left(I R_{i}\left(h_{k}\right)\right)$ Constraint. The individual rationality constraint in a dynamic environment is $S\left(\theta_{i} \mid h_{k}\right) \geq 0$ for $h_{k} \in \boldsymbol{H}_{k}$.

Capacity Constraint $\left(C C\left(h_{k}\right)\right)$. In view of the same hire time for all customers, the capacity constraint at each time point $t_{k}$ is that the total number of allocated units cannot exceed $C$. At time $t_{0}$, the capacity constraint is $M\left(f_{H} q_{H}+f_{L} q_{L}\right) \leq C$. When $k>0, \boldsymbol{H}_{k}$ can be divided into three subsets, $\boldsymbol{H}_{k}=\left\{h_{k}^{\hat{L}}, h_{k}^{H}, h_{k}^{L}\right\}$, where $h_{k}^{\hat{L}}=(L, \cdots, L)$ is the consistent low-type history from time $t_{0}$ to time $t_{k-1}$ where the customer types are all $L$ in the first $k$ time points; $h_{k}^{H}=\left\{h_{k-1}, H\right\}$ refers to the history where the customer type at $t_{k-1}$ is $H$ and $h_{k}^{L}=\left\{h_{k-1}, L\right\}$ is the history where the customer type at $t_{k-1}$ is $L$ and $h_{k-1} \neq h_{k-1}^{L}$. Note that $f\left(h_{1}^{L}\right)=0$. The containers rented out at time point $t_{k-1}$ will be returned to the company at the time point $t_{k}$. The capacity constraint at each time point $t_{k}$ can be expressed as

$$
M\left[f\left(h_{k}^{\hat{L}}\right) \sum_{i} f_{L i} q_{i}\left(h_{k}^{\hat{L}}\right)+f\left(h_{k}^{H}\right) \sum_{i} f_{H i} q_{i}\left(h_{k}^{H}\right)+f\left(h_{k}^{L}\right) \sum_{i} f_{L i} q_{i}\left(h_{k}^{L}\right)\right] \leq C
$$

The monopolist's problem boils down to as follows.

$$
\begin{aligned}
& \Pi(Q, P)= \max _{\{Q, P\}} M\left\{\sum_{i} f_{i}\left(P_{i}-Y-a d q_{i}\right)+\sum_{k=1}^{K} \delta^{k d} \mathbb{E}_{h_{k}^{z}} \sum_{i} f_{z i}\left[P_{i}\left(h_{k}^{z}\right)-Y-a d q_{i}\left(h_{k}^{z}\right)\right]\right\} \\
&=\max _{\{Q, S(\theta)\}} M\left\{\sum_{i} f_{i}\left[U\left(\theta_{i}, q_{i}\right)-S\left(\theta_{i}\right)-Y-a d q_{i}\right]\right. \\
&\left.\quad+\sum_{k=1}^{K} \delta^{k d} \mathbb{E}_{h_{k}^{z}} \sum_{i} f_{z i}\left[U\left(\theta_{i}, q_{i}\left(h_{k}^{z}\right)\right)-Y-a d q_{i}\right]\right\}
\end{aligned}
$$

s.t. $I C_{i j}\left(h_{k}\right), I R_{i}\left(h_{k}\right), C C\left(h_{k}\right)$

$$
\forall i, j \in\{L, H\}, h_{k} \in \boldsymbol{H}_{k}(0 \leq k \leq K)
$$


Battaglini and Lamba (2014) proved that the first-order approach is valid for the monotonic allocations in a dynamic environment, $q\left(h_{k}\right) \geq q\left(h_{k^{\prime}}\right)$ if $h_{k}>h_{k^{\prime}}$, e.g. $h_{k}=\{H, L\}$ and $h_{k^{\prime}}=\{L, L\}$ in our problem. Since we only have two customer types and unidimensional allocation under the monotone hazard rate assumption, the monotonic allocation requirement is satisfied in our problem. We adopt the relaxed method as presented in the standard static nonlinear pricing problem where the the incentive compatibility constraints for the high type $I C_{H L}\left(h_{k}\right)$ and the individual rationality constraints for the low type $I R_{L}\left(h_{k}\right)$ are binding for any $h_{k} \in \boldsymbol{H}_{k}$. Define the relaxed problem as $I R_{L}\left(h_{k}\right)$ and $I C_{H L}\left(h_{k}\right)$ are binding constraints for any $h_{k} \in \boldsymbol{H}_{k}$.

Lemma 4.1. In a dynamic environment with same hire time preference, the optimal solution of the relaxed problem is also an optimal solution of the original problem.

Proof. Suppose that $\{Q, P\}$ is an optimal solution of the original problem which $I R_{L}\left(h_{k}\right)$ and $I C_{H L}\left(h_{k}\right)$ are not binding constraints for some $h_{k} \in \boldsymbol{H}_{k}$.

If $I R_{L}\left(h_{k}\right)$ are not binding constraints for some $h_{k} \in \boldsymbol{H}_{k}$, that is, $S\left(\theta_{L} \mid h_{k}\right)=\omega$, where $\omega$ is a positive number.

- When $k=0$, consider an alternative solution $\left\{Q^{\prime}, S^{\prime}(\theta)\right\}$ such that $S^{\prime}\left(\theta_{L}\right)=$ $S\left(\theta_{L}\right)-\omega$. Then the expected optimal profit increases by $f_{L} \omega, \Pi\left(Q^{\prime}, S^{\prime}(\theta)\right)=$ $\Pi(Q, P)+M f_{L} \omega$.

- When $k>0$, let $S^{\prime}\left(\theta_{L} \mid h_{k}\right)=S\left(\theta_{L} \mid h_{k}\right)-\omega$, the expected profit remains the same satisfying all constraints, $\Pi\left(Q^{\prime}, S^{\prime}(\theta)\right)=\Pi(Q, P)$.

If $I C_{H L}\left(h_{k}\right)$ are not binding constraints for some $h_{k} \in \boldsymbol{H}_{k}, S\left(\theta_{H} \mid h_{k}\right)=\Delta \theta q_{L}\left(h_{k}\right)+$ $\delta^{d} \Delta f S\left(\theta_{H} \mid h_{k+1}^{L}\right)+\omega$, where $\Delta f=f_{H H}-f_{L H}$. Consider an alternative solution $\left\{Q^{\prime}, S^{\prime}(\theta)\right\}$ such that $S^{\prime}\left(\theta_{H} \mid h_{k}\right)=S\left(\theta_{H} \mid h_{k}\right)-\omega$.

- When $k=0$, the net change is $f_{H} \omega, \Pi\left(Q^{\prime}, S^{\prime}(\theta)\right)=\Pi(Q, P)+M f_{H} \omega$.

- When $k>0$ and $k^{\prime}>k, S^{\prime}\left(\theta_{H} \mid h_{k^{\prime}}\right)$ remains the same as in the original solution, $S^{\prime}\left(\theta_{H} \mid h_{k^{\prime}}\right)=S\left(\theta_{H} \mid h_{k^{\prime}}\right)$. When $k^{\prime}=k-1$, we have $S^{\prime}\left(\theta_{H} \mid h_{k-1}\right)=$ $S\left(\theta_{H} \mid h_{k-1}\right)-\delta^{d} \omega$. By repeatedly applying the above modifications until $k^{\prime}=0, S^{\prime}\left(\theta_{H}\right)=S\left(\theta_{H}\right)-\delta^{k d} \omega$. The expected optimal profit increases by $M f_{H} \delta^{k d} \omega, \Pi\left(Q^{\prime}, S^{\prime}(\theta)\right)=\Pi(Q, P)+M f_{H} \delta^{k d} \omega$. 
Based on the above, the alternative solution satisfying the binding constraints $I C_{H L}\left(h_{k}\right)$ and $I R_{L}\left(h_{k}\right)$ in the relaxed problem yields an equal or higher profit, which contradicts the optimality of the assumption.

From the binding constraint $I C_{H L}\left(h_{k}\right)$ in the relaxed problem,

$$
S\left(\theta_{H} \mid h_{k}\right)=\Delta \theta q_{L}\left(h_{k}\right)+\delta^{d} \Delta f S\left(\theta_{H} \mid h_{k+1}^{L}\right), \text { where } \Delta f=f_{H H}-f_{L H},
$$

the expected consumer surplus $S\left(\theta_{H}\right)$ is

$$
S\left(\theta_{H}\right)=S\left(\theta_{H} \mid h_{0}\right)=\Delta \theta \sum_{k=0}^{K}\left(\delta^{d} \Delta f\right)^{k} q_{L}\left(h_{k}^{\hat{L}}\right)
$$

As $S\left(\theta_{L} \mid h_{k}\right)=0$ and $S\left(\theta_{H}\right)$ depends on $q_{L}\left(h_{k}^{\hat{L}}\right)$ for $k=\{0,1, \cdots, K\}$, reformulate (8) as the Lagrangean objective function. The relaxed problem is written as follows.

$$
\begin{gathered}
\Pi\left(Q, S\left(\theta_{H}\right), \Lambda\right)=\max _{\left\{Q, S\left(\theta_{H}\right), \Lambda\right\}} M\left[\sum_{i} f_{i}\left(U\left(\theta_{i}, q_{i}\right)-Y-a d q_{i}\right)-f_{H} S\left(\theta_{H}\right)\right] \\
+M \sum_{k=1}^{K} \delta^{k d} \mathbb{E}_{h_{k}^{z}} \sum_{i} f_{z i}\left[U\left(\theta_{i}, q_{i}\left(h_{k}^{z}\right)\right)-Y-a d q_{i}\left(h_{k}^{z}\right)\right]+\lambda_{0}\left(\frac{C}{M}-f_{H} q_{H}-f_{L} q_{L}\right) \\
+\sum_{k=1}^{K} \lambda_{k}\left[\frac{C}{M}-f\left(h_{k}^{\hat{L}}\right) \sum_{i} f_{L i} q_{i}\left(h_{k}^{\hat{L}}\right)-f\left(h_{k}^{H}\right) \sum_{i} f_{H i} q_{i}\left(h_{k}^{H}\right)-f\left(h_{k}^{L}\right) \sum_{i} f_{L i} q_{i}\left(h_{k}^{L}\right)\right] \\
\text { s.t. } \quad I R_{L}\left(h_{k}\right) \\
\quad S\left(\theta_{H}\right)=\Delta \theta \sum_{k=0}^{K}\left(h_{k}\right)=0 \quad I C_{H L}\left(h_{k}\right) \\
\forall i \in\{L, H\}, h_{k} \in \boldsymbol{H}_{k}(0 \leq k \leq K)
\end{gathered}
$$

Theorem 4.1. For any $h_{k} \in \boldsymbol{H}_{k}$, the optimal intertemporal allocation policy for customers with same hire time preference is characterized as follows.

At time 0,

$$
\left\{\begin{array}{l}
q_{H}=\theta_{H}-a d-\Lambda_{0} ; \\
q_{L}=\theta_{L}-a d-\frac{f_{H}}{f_{L}} \Delta \theta-\Lambda_{0} ; \quad \text { where } \Lambda_{0}=\frac{\lambda_{0}}{M}=\left(\theta_{L}-a d-\frac{C}{M}\right)^{+}
\end{array}\right.
$$

when $h_{k} \in\left\{h_{k}^{H}, h_{k}^{L}\right\}$, when $h_{k}=h_{k}^{\hat{L}}$,

$$
\left\{\begin{array} { l } 
{ q _ { H } ( h _ { k } ) = \theta _ { H } - a d - \Lambda _ { k } ; } \\
{ q _ { L } ( h _ { k } ) = \theta _ { L } - a d - \Lambda _ { k } ; }
\end{array} \left\{\begin{array}{l}
q_{H}\left(h_{k}^{\hat{L}}\right)=\theta_{H}-a d-\Lambda_{k} \\
q_{L}\left(h_{k}^{\hat{L}}\right)=\theta_{L}-a d-\frac{f_{H} \Delta \theta}{f_{L}}\left(\frac{\Delta f}{f_{L L}}\right)^{k}-\Lambda_{k}
\end{array}\right.\right.
$$

where $\Lambda_{k}=\frac{\lambda_{k}}{M \delta^{k d}}=\left\{\theta_{L}-a d-\frac{C}{M}+\Delta \theta\left[f_{L H}\left(f\left(h_{k}^{\hat{L}}\right)+f\left(h_{k}^{L}\right)\right)+f\left(h_{k}^{H}\right) f_{H H}-f_{H} \Delta f^{k}\right]\right\}^{+}$. 
Proof. When $h_{k} \in\left\{h_{k}^{H}, h_{k}^{L}\right\}$, the first-order conditions w.r.t $q_{H}\left(h_{k}\right)$ and $q_{L}\left(h_{k}\right)$ are given by the following equations.

$$
\begin{array}{rr}
q_{H}\left(h_{k}\right): & M \delta^{k d}\left[\theta_{H}-a d-q_{H}\left(h_{k}\right)\right]-\lambda_{k}=0 \\
q_{L}\left(h_{k}\right): & M \delta^{k d}\left[\theta_{L}-a d-q_{L}\left(h_{k}\right)\right]-\lambda_{k}=0
\end{array}
$$

When $h_{k}=h_{k}^{\hat{L}}$, the first-order conditions about $q_{H}\left(h_{k}^{\hat{L}}\right)$ and $q_{L}\left(h_{k}^{\hat{L}}\right)$ are given by the following equations.

$$
\begin{array}{cc}
q_{H}\left(h_{k}^{\hat{L}}\right): & M \delta^{k d}\left[\theta_{H}-a d-q_{H}\left(h_{k}^{\hat{L}}\right)\right]-\lambda_{k}=0 \\
q_{L}\left(h_{k}^{\hat{L}}\right): & M \delta^{k d}\left[\theta_{L}-a d-q_{L}\left(h_{k}^{\hat{L}}\right)-\frac{f_{H} \Delta \theta}{f_{L}}\left(\frac{\Delta f}{f_{L L}}\right)^{k}\right]-\lambda_{k}=0
\end{array}
$$

And $\Lambda_{k}$ is obtained from the following equation $\left[f\left(h_{k}^{\hat{L}}\right) \sum_{i} f_{L i} q_{i}\left(h_{k}^{\hat{L}}\right)+f\left(h_{k}^{H}\right) \sum_{i} f_{H i} q_{i}\left(h_{k}^{H}\right)+f\left(h_{k}^{L}\right) \sum_{i} f_{L i} q_{i}\left(h_{k}^{L}\right)-\frac{C}{M}\right]^{+}=0$.

Corollary 4.1. For $0 \leq k \leq K, \Lambda_{k}$ is increasing ${ }^{2}$ in $k$.

Proof. We use induction to prove this lemma. For $k=1, \Lambda_{1}-\Lambda_{0}=f_{L H} \Delta \theta>0$. Next, we show that if $\Lambda_{k}-\Lambda_{k-1}>0$, then also $\Lambda_{k+1}-\Lambda_{k}>0$ holds. Note that

$$
\begin{aligned}
& \left\{\begin{aligned}
f\left(h_{k}^{\hat{L}}\right)= & f\left(h_{k-1}^{\hat{L}}\right) f_{L L} ; \\
f\left(h_{k}^{L}\right)= & f\left(h_{k-1}^{L}\right) f_{L L}+f\left(h_{k-1}^{H}\right) f_{H L} ; \\
f\left(h_{k}^{H}\right)= & f\left(h_{k-1}^{H}\right) f_{H H}+f\left(h_{k-1}^{L}\right) f_{L H}+f\left(h_{k-1}^{\hat{L}}\right) f_{L H} .
\end{aligned}\right. \\
& \frac{\Lambda_{k}-\Lambda_{k-1}}{\Delta \theta}=\Delta f\left[f_{L H}\left(f\left(h_{k-1}^{L}\right)+f\left(h_{k-1}^{\hat{L}}\right)\right)-f_{H L} f\left(h_{k-1}^{H}\right)\right] \\
& \quad+f_{H} \Delta f^{k-1}(1-\Delta f)>0
\end{aligned}
$$

Suppose that if the above equation is positive,

$$
\begin{aligned}
\frac{\Lambda_{k+1}-\Lambda_{k}}{\Delta \theta}= & f_{L H}\left[f\left(h_{k+1}^{\hat{L}}\right)-f\left(h_{k}^{\hat{L}}\right)+f\left(h_{k+1}^{L}\right)-f\left(h_{k}^{L}\right)\right] \\
& +f_{H H}\left[f\left(h_{k+1}^{H}\right)-f\left(h_{k}^{H}\right)\right]+f_{H} \Delta f^{k}(1-\Delta f) \\
= & \Delta f\left\{\Delta f\left[f_{L H}\left(f\left(h_{k-1}^{\hat{L}}\right)+f\left(h_{k-1}^{L}\right)\right)-f_{H L} f\left(h_{k-1}^{H}\right)\right]\right. \\
& \left.+f_{H} \Delta f^{k-1}(1-\Delta f)\right\}>0
\end{aligned}
$$

${ }^{2}$ The increase and decrease in our paper refer to the weak sense. 
As $\Lambda_{k}$ increases with $k$, it indicates that the effect of capacity constraint at each time point increases over time. The optimal quantity $q_{i}\left(h_{k}\right)$ for $h_{k} \in\left\{h_{k}^{H}, h_{k}^{L}\right\}$ and $q_{H}\left(h_{k}^{\hat{L}}\right)$ diminishes as $\Lambda_{k}$ grows; while the trend of $q_{L}\left(h_{k}^{\hat{L}}\right)$ as $k$ increases depends on the mixed effects which are the decrement of $\frac{f_{H} \Delta \theta}{f_{L}}\left(\frac{\Delta f}{f_{L L}}\right)^{k}\left(1-\frac{\Delta f}{f_{L L}}\right)$ and the increment of $\Lambda_{k}-\Lambda_{k-1}$. Additionally, the capacity constraint at each time point binds the optimal quantity after any history $h_{k}$. In Battaglini (2005), the uncapacitated and infinite version of our problem, the optimal quantity converges to the efficient quantity $\theta_{i}\left(\theta_{i}-a d\right.$ in our context) due to $\frac{\Delta f}{f_{L L}}<1$.

\subsubsection{Different hire time preferences $\left(\bar{d}_{H}>\bar{d}_{L}\right)$}

In this subsection, we discuss the problem with two types of customers having different preferred hire time $\bar{d}_{H}>\bar{d}_{L}$. Unlike the previous section, there are fixed but not equidistant time points in the finite horizon, $\left\{t_{0}=0, t_{1}=\bar{d}_{L}, t_{2}=\right.$ $\left.\bar{d}_{H}, \cdots, t_{K}, t_{K+1}=T\right\}$. Assume that each customer has at most one rental contract at any time point. The corresponding monopolist's optimization problem can be formulated as follows.

$$
\begin{array}{cc}
\max _{\{Q, S(\theta)\}} M\left\{\sum_{i} f_{i}\left(P_{i}-Y-a \bar{d}_{i} q_{i}\right)+\sum_{k=1}^{K} \delta^{t_{k}} \mathbb{E}_{h_{k}^{z}} \sum_{i} f_{z i}\left[P_{i}-Y-a \bar{d}_{i} q_{i}\left(h_{k}^{z}\right)\right]\right\} \\
\text { s.t. } \quad S\left(\theta_{i} \mid h_{k}\right) \geq S\left(\theta_{j} \mid h_{k}\right)+\Delta \theta q_{j}\left(h_{k}\right)+\delta^{\bar{d}_{j}} \sum_{l}\left(f_{i l}-f_{j l}\right) S\left(\theta_{l} \mid h_{k+1}^{j}\right) & I C_{i j}\left(h_{k}\right) \\
S\left(\theta_{i} \mid h_{k}\right) \geq 0 & I R_{i}\left(h_{k}\right) \\
M\left(f_{H} q_{H}+f_{L} q_{L}\right) \leq C & C C\left(h_{0}\right) \\
f_{z L} q_{L}\left(h_{k}^{z}\right)+f_{z H} q_{H}\left(h_{k}^{z}\right) \leq q_{z}\left(h_{k-1}\right) \quad h_{k}^{z}=\left\{h_{k-1}, z\right\} & \\
\left.\forall i, j, l \in\{L, H\}, h_{k} \in h_{k}\right)
\end{array}
$$

Note that $\triangle \theta=\theta_{H}-\theta_{L}=\bar{\theta}_{H} \bar{d}_{H}-\bar{\theta}_{L} \bar{d}_{L}$. The capacity constraint $C C\left(h_{k}\right)(k>0)$ in this model is different from that in the model of customers with the same hire time. In the previous section, with equidistant time points, the available capacity at each time point is $C$; whereas in this section, the time points in the horizon are not equidistant anymore, the available capacity at time point $t_{k}$ is the number of rented containers at $t_{k-1}, q_{z}\left(h_{k-1}\right)$. We still apply the relaxed method to solve this problem.

Lemma 4.2. In a dynamic environment with different hire time preferences, the optimal solution of the relaxed problem is also an optimal solution of the original problem. 
Proof. The proof is similar to the proof of Lemma 4.1, except the part $I C_{H L}\left(h_{k}\right)$ when $k>0$.

If $I C_{H L}\left(h_{k}\right)$ are not binding constraints in an optimal solution $\{Q, P\}$ of the original problem for some $h_{k} \in \boldsymbol{H}_{k}$, then $S\left(\theta_{H} \mid h_{k}\right)=\Delta \theta q_{L}\left(h_{k}\right)+\delta^{\bar{d}_{L}} \Delta f S\left(\theta_{H} \mid h_{k+1}^{L}\right)+$ $\omega$. Consider an alternative solution $\left\{Q^{\prime}, S^{\prime}(\theta)\right\}$ such that $S^{\prime}\left(\theta_{H} \mid h_{k}\right)=S\left(\theta_{H} \mid h_{k}\right)-\omega$.

When $k>0$ and $k^{\prime}>k, S^{\prime}\left(\theta_{H} \mid h_{k^{\prime}}\right)$ remains the same as in the original solution, $S^{\prime}\left(\theta_{H} \mid h_{k^{\prime}}\right)=S\left(\theta_{H} \mid h_{k^{\prime}}\right)$. When $k^{\prime}=k-1$, we have $S^{\prime}\left(\theta_{H} \mid h_{k-1}\right)=$ $S\left(\theta_{H} \mid h_{k-1}\right)-\delta^{\bar{d}_{L}} \omega$. By repeatedly applying the above modifications until $k^{\prime}=0$, $S^{\prime}\left(\theta_{H}\right)=S\left(\theta_{H}\right)-\delta^{k \bar{d}_{L}} \omega$. The expected optimal profit increases by $M f_{H} \delta^{k \bar{d}_{L}} \omega$, $\Pi\left(Q^{\prime}, S^{\prime}(\theta)\right)=\Pi(Q, P)+M f_{H} \delta^{k \bar{d}_{L}} \omega$. It contradicts the optimality of the assumption.

Use the Lagrange multiplier approach to reformulate the relaxed problem as

$$
\begin{aligned}
& \Pi\left(Q, S\left(\theta_{H}\right), \Lambda\right)=\max _{\left\{Q, S\left(\theta_{H}\right), \Lambda\right\}} M\left\{\sum_{i} f_{i}\left[\theta_{i} q_{i}-\frac{1}{2}\left(q_{i}^{2}+\bar{d}_{i}^{2}\right)-Y-a \bar{d}_{i} q_{i}\right]-f_{H} S\left(\theta_{H}\right)\right. \\
& \left.+\sum_{k=1}^{K} \delta^{t_{k}} \mathbb{E}_{h_{k}^{z}} \sum_{i} f_{z i}\left[\theta_{i} q_{i}\left(h_{k}^{z}\right)-\frac{1}{2}\left(q_{i}^{2}\left(h_{k}^{z}\right)+\bar{d}_{i}^{2}\right)-Y-a \bar{d}_{i} q_{i}\left(h_{k}^{z}\right)\right]\right\} \\
& +\lambda_{0}\left(\frac{C}{M}-f_{H} q_{H}-f_{L} q_{L}\right)+\sum_{k=1}^{K} \lambda_{k}\left[q_{z}\left(h_{k-1}\right)-f_{z L} q_{L}\left(h_{k}\right)-f_{z H} q_{H}\left(h_{k}\right)\right] \\
& \text { s.t. } \quad S\left(\theta_{L} \mid h_{k}\right)=0 \quad I R_{L}\left(h_{k}\right) \\
& \qquad \begin{array}{l}
\quad S\left(\theta_{H}\right)=\Delta \theta \sum_{k=0}^{K}\left(\delta^{\bar{d}_{L}} \Delta f\right)^{k} q_{L}\left(h_{k}^{\hat{L}}\right) \quad I C_{H L}\left(h_{k}\right) \\
\forall i \in\{L, H\}, h_{k} \in \boldsymbol{H}_{k}(0 \leq k \leq K)
\end{array}
\end{aligned}
$$

Theorem 4.2. For any $h_{k} \in \boldsymbol{H}_{k}$, the optimal intertemporal allocation policy for customers with different hire time preferences is characterized as follows.

At time 0,

$$
\left\{\begin{array}{l}
q_{H}=\theta_{H}-a \bar{d}_{H}-\Lambda_{0} ; \\
q_{L}=\theta_{L}-a \bar{d}_{L}-\frac{f_{H}}{f_{L}} \Delta \theta-\Lambda_{0} ;
\end{array} \quad \text { where } \Lambda_{0}=\frac{\lambda_{0}}{M}=\left[\theta_{L}-a\left(f_{H} \bar{d}_{H}+f_{L} \bar{d}_{L}\right)-\frac{C}{M}\right]^{+}\right.
$$

when $h_{k} \in\left\{h_{k}^{H}, h_{k}^{L}\right\}$,

$$
\left\{\begin{array}{l}
q_{H}\left(h_{k}\right)=\theta_{H}-a \bar{d}_{H}-\Lambda_{k} \\
q_{L}\left(h_{k}\right)=\theta_{L}-a \bar{d}_{L}-\Lambda_{k}
\end{array}\right.
$$

where $\Lambda_{k}=\frac{\lambda_{k}}{M \delta^{t} k f\left(h_{k}\right)}=\left[f_{z H} \theta_{H}+f_{z L} \theta_{L}-\theta_{z}-a\left(f_{z H} \bar{d}_{H}+f_{z L} \bar{d}_{L}-\bar{d}_{z}\right)+\Lambda_{k-1}\right]^{+}$; 
when $h_{k}=h_{k}^{\hat{L}}$,

$$
\left\{\begin{array}{l}
q_{H}\left(h_{k}^{\hat{L}}\right)=\theta_{H}-a \bar{d}_{H}-\Lambda_{k} \\
q_{L}\left(h_{k}^{\hat{L}}\right)=\theta_{L}-a \bar{d}_{L}-\frac{f_{H} \Delta \theta}{f_{L}}\left(\frac{\Delta f}{f_{L L}}\right)^{k}-\Lambda_{k}
\end{array}\right.
$$

where $\Lambda_{k}=\frac{\lambda_{k}}{M \delta^{k \bar{d}} f\left(h_{k}^{\hat{L}}\right)}=\left[f_{L H}\left(\Delta \theta-a \bar{d}_{H}+a \bar{d}_{L}\right)+\frac{f_{H} \Delta \theta}{f_{L}}\left(\frac{\Delta f}{f_{L L}}\right)^{k-1}(1-\Delta f)+\Lambda_{k-1}\right]^{+}$. Proof. $q_{i}\left(h_{k}\right)$ exists in the capacity constraints $C C\left(h_{k}\right)$ and $C C\left(h_{k+1}\right) . C C\left(h_{k}\right)$ binds the optimal allocated quantity $q_{i}\left(h_{k}\right)$, while $C C\left(h_{k+1}\right)$ decreases the binding effect due to the returning process. Thus, we consider the optimal allocation policy under the tightened binding capacity effect $C C\left(h_{k}\right)$. When $h_{k} \in\left\{h_{k}^{H}, h_{k}^{L}\right\}$, the first-order conditions w.r.t $q_{H}\left(h_{k}\right)$ and $q_{L}\left(h_{k}\right)$ are given by the following equations.

$$
\begin{array}{ll}
q_{H}\left(h_{k}\right): & M \delta^{t_{k}} f\left(h_{k}\right)\left[\theta_{H}-a \bar{d}_{H}-q_{H}\left(h_{k}\right)\right]-\lambda_{k}=0 \\
q_{L}\left(h_{k}\right): & M \delta^{t_{k}} f\left(h_{k}\right)\left[\theta_{L}-a \bar{d}_{L}-q_{L}\left(h_{k}\right)\right]-\lambda_{k}=0
\end{array}
$$

And $\Lambda_{k}=\left[f_{z H}\left(\theta_{H}-a \bar{d}_{H}\right)+f_{z L}\left(\theta_{L}-a \bar{d}_{L}\right)-q_{z}\left(h_{k-1}\right)\right]^{+}=\left[f_{z H} \theta_{H}+f_{z L} \theta_{L}-\theta_{z}-\right.$ $\left.a\left(f_{z H} \bar{d}_{H}+f_{z L} \bar{d}_{L}-\bar{d}_{z}\right)+\Lambda_{k-1}\right]^{+}$.

When $h_{k}=h_{k}^{\hat{L}}$, the first-order conditions w.r.t $q_{H}\left(h_{k}^{\hat{L}}\right)$ and $q_{L}\left(h_{k}^{\hat{L}}\right)$ are given by the following equations.

$$
\begin{array}{rc}
q_{H}\left(h_{k}^{\hat{L}}\right): & M \delta^{t_{k}} f\left(h_{k}^{\hat{L}}\right)\left[\theta_{H}-a \bar{d}_{H}-q_{H}\left(h_{k}^{\hat{L}}\right)\right]-\lambda_{k}=0 \\
q_{L}\left(h_{k}^{\hat{L}}\right): & M \delta^{t_{k}} f\left(h_{k}^{\hat{L}}\right) f_{L L}\left[\theta_{L}-a \bar{d}_{L}-q_{L}\left(h_{k}^{\hat{L}}\right)\right]-\lambda_{k} f_{L L}-M \delta^{t_{k}} f_{H} \Delta \theta \Delta f^{k}=0 \\
\Lambda_{k}= & {\left[f_{L H}\left(\theta_{H}-a \bar{d}_{H}\right)+f_{L L}\left(\theta_{L}-a \bar{d}_{L}-\frac{f_{H} \Delta \theta}{f_{L}}\left(\frac{\Delta f}{f_{L L}}\right)^{k}\right)-q_{L}\left(h_{k-1}^{L}\right)\right]^{+}} \\
= & {\left[f_{L H}\left(\Delta \theta-a \bar{d}_{H}+a \bar{d}_{L}\right)+\frac{f_{H} \Delta \theta}{f_{L}}\left(\frac{\Delta f}{f_{L L}}\right)^{k-1}(1-\Delta f)+\Lambda_{k-1}\right]^{+} .}
\end{array}
$$

Corollary 4.2. For $0 \leq k \leq K$ and any $h_{k}^{z} \in \boldsymbol{H}_{k}$, if $z=L, \Lambda_{k}$ increases with $k$; if $z=H, \Lambda_{k}$ decreases with $k$.

Proof. We prove this corollary by induction. To begin with, consider the case $z=L$.

Step 1. For $k=1, h_{1}=\{\mathrm{E}\}=h_{1}^{\hat{L}}$.

$$
\begin{aligned}
\Lambda_{1}-\Lambda_{0} & =f_{L H}\left(\Delta \theta-a \bar{d}_{H}+a \bar{d}_{L}\right)+\frac{f_{H} \Delta \theta}{f_{L}}(1-\Delta f) \\
& =f_{L H}\left[\bar{d}_{H}\left(\bar{\theta}_{H}-a\right)-\bar{d}_{L}\left(\theta_{L}-a\right)\right]+\frac{f_{H} \Delta \theta}{f_{L}}(1-\Delta f) \\
& >f_{L H}\left(\theta_{L}-a\right)\left(\bar{d}_{H}-\bar{d}_{L}\right)+\frac{f_{H} \Delta \theta}{f_{L}}(1-\Delta f)>0
\end{aligned}
$$


The positivity is derived from $\bar{\theta}_{L}>a, \bar{d}_{H}>\bar{d}_{L}$ and $\Delta f=f_{H H}-f_{L H}<1$.

Step 2. If $h_{k}=h_{k}^{L}, \Lambda_{k}=\left[f_{L H}\left(\Delta \theta-a \bar{d}_{H}+a \bar{d}_{L}\right)+\Lambda_{k-1}\right]^{+}$; if $h_{k}=h_{k}^{\hat{L}}$, $\Lambda_{k}=\left[f_{L H}\left(\Delta \theta-a \bar{d}_{H}+a \bar{d}_{L}\right)+\frac{f_{H} \Delta \theta}{f_{L}}\left(\frac{\Delta f}{f_{L L}}\right)^{k-1}(1-\Delta f)+\Lambda_{k-1}\right]^{+}$. As $\Delta \theta-a \bar{d}_{H}+a \bar{d}_{L}>0$ and $1-\Delta f>0$, we have $\Lambda_{k} \geq \Lambda_{k-1}$.

Consider the case when $z=H$. For $k \in\{1, \cdots, K\}, \Lambda_{k}=\left[-f_{H L}\left(\Delta \theta-a \bar{d}_{H}+\right.\right.$ $\left.\left.a \bar{d}_{L}\right)+\Lambda_{k-1}\right]^{+}$, hence $\Lambda_{k} \leq \Lambda_{k-1}$.

In this subsection, it is interesting that the effect of capacity constraint becomes smaller whenever the last customer type is the high type and this effect becomes larger whenever the last customer type is the low type no matter the history is $h_{k}^{L}$ or $h_{k}^{\hat{L}}$. In other words, the influence of capacity constraint depends only on the realization of the customer type in the previous period. Based on the monotonicity of $\Lambda_{k}$, the optimal quantity of the consistent high type converges to the efficient quantity level $\left(\theta_{H}-a \bar{d}_{H}\right)$ over time. At the same time, the distortion of the (highly consistent or inconsistent) low type customer becomes greater over time. The situation that the effect of capacity constraints depends on customer type contrasts with the effect of capacity constraint which is independent of customer type in Section 4.1.1. For the case with same hire time preference, the capacity constraint binds all the allocated quantities at each time point, while in this case with different hire time preferences, the capacity constraint only takes effect on the next allocation.

\subsection{Hire quantity preference}

Denote the preferred hire quantities of two customer types by $\bar{q}_{H}$ and $\bar{q}_{L}$. We first study the case that $\bar{q}_{H}=\bar{q}_{L}$ and then discuss the case when $\bar{q}_{H}>\bar{q}_{L}$. Let $\theta_{i}=\bar{\theta}_{i} \bar{q}_{i}$.

\subsubsection{Same hire quantity preference $\left(\bar{q}_{H}=\bar{q}_{L}=q\right)$}

In this section, we analyze the case that both customer types have the same hire quantity preference. The monopolist's problem is to determine a optimal hire time sequence $D=\left\{d_{i}\left(h_{0}\right), d_{i}\left(h_{1}\right), \cdots, d_{i}\left(h_{k}\right)\right\}$ for any $h_{k} \in \boldsymbol{H}_{k}(k=0,1, \cdots, N)$ to maximize the expected profit, where $d_{i}\left(h_{k}\right)$ is the hire time of customer type $i$ after history $h_{k}$ and $N$ is the total number of rental contracts for history $h_{k}^{\hat{L}}$ in the horizon. $t_{i}\left(h_{k}\right)$ is the beginning time of rental contract for type $i$ after history $h_{k}$, $t_{i}\left(h_{k}\right)=\sum_{l=0}^{k-1} d\left(h_{l}\right)\left(h_{l} \in h_{k}\right)$. The optimization problem in this setting is written 
as shown below.

$$
\begin{gathered}
\Pi(D, S(\theta))=\max _{\{D, S(\theta)\}} M\left(\sum_{i} f_{i}\left[U\left(\theta_{i}, d_{i}\left(h_{0}\right)\right)-S\left(\theta_{i}\right)-Y-a q d_{i}\left(h_{0}\right)\right]\right. \\
\left.+\sum_{k=1}^{N} \mathbb{E}_{h_{k}^{z}} \sum_{j} \delta^{t_{j}\left(h_{k}^{z}\right)} f_{z j}\left[U\left(\theta_{j}, d_{j}\left(h_{k}^{z}\right)\right)-Y-a q d_{i}\left(h_{k}^{z}\right)\right]\right) \\
\text { s.t. } \quad S\left(\theta_{i} \mid h_{k}\right) \geq S\left(\theta_{j} \mid h_{k}\right)+\Delta \theta d_{j}\left(h_{k}\right)+\delta^{d_{j}\left(h_{k}\right)} \sum_{l}\left(f_{i l}-f_{j l}\right) S\left(\theta_{l} \mid h_{k+1}^{j}\right) \quad I C_{i j}\left(h_{k}\right) \\
S\left(\theta_{i} \mid h_{k}\right) \geq 0 \\
\quad t_{i}\left(h_{k}\right)+d_{i}\left(h_{k}\right) \leq T
\end{gathered}
$$

The last constraint is the finite time constraint for hire time sequence $\mathrm{D}$ with respect to $h_{k}$. That is, for any $h_{k} \in \boldsymbol{H}_{k}$, the summation of the hire time of all rental contracts cannot exceed the planning horizon $T$. As customers have hire quantity preference, there is no capacity constraint for the problem. Unfortunately, as the following example shows, even $N=2$, a closed form solution is unlikely derivable.

Example $(\mathbf{N}=2)$ Suppose that at time $t_{0}=0$ the types of all arriving customers are $H$, then at time point $t_{1}=d_{H}\left(h_{0}\right)$, the hire time for the low type and the high type are $\theta_{L}-a q$ and $\theta_{H}-a q$, respectively. The objective function of the monopolist is

$$
\begin{aligned}
\Pi(D, S(\theta))= & \max _{d_{H}\left(h_{0}\right)} M f_{H}\left\{\theta_{H} d_{H}\left(h_{0}\right)-\frac{1}{2}\left(d_{H}^{2}\left(h_{0}\right)+q^{2}\right)-Y-a \bar{q}_{H} d_{H}\left(h_{0}\right)\right. \\
& \left.+\frac{1}{2} \delta^{d_{H}\left(h_{0}\right)} \pi\left(\theta_{H}, \theta_{L}\right)\right\}
\end{aligned}
$$

where $\pi\left(\theta_{H}, \theta_{L}\right)=f_{H H}\left(\theta_{H}^{2}-a^{2} q^{2}\right)+f_{H L}\left(\theta_{L}^{2}-a^{2} q^{2}\right)-q^{2}$. The first order condition w.r.t $d_{H}\left(h_{0}\right)$ is

$$
\theta_{H}-a q-d_{H}\left(h_{0}\right)+\frac{1}{2} \delta^{d_{H}\left(h_{0}\right)} \ln d_{H}\left(h_{0}\right) \pi\left(\theta_{H}, \theta_{L}\right)=0
$$

As $d_{H}\left(h_{0}\right)$ lies in the exponent, the above equation is a transcendental equation which does not exist a closed form solution. The first decision variable $d_{i}\left(h_{0}\right)$ influences all the following decision variables $d_{i}\left(h_{k}\right)(k=1, \cdots, N)$. This contrasts with the problem in a dynamic environment when customers have hire time preference. Because in the problem discussed in Section 4.1 the decision variable such as $q_{i}\left(h_{k}\right)$ only affects the next decision variables $q_{i}\left(h_{k+1}\right)$ through available capacity constraint rather than all subsequent decision variables. 
In view of this, we limit the choices of possible hire time. Suppose that the alternative hire time sets for both types are $D_{L}=\left\{d_{L}^{1}, d_{L}^{2}, \cdots, d_{L}^{K}\right\}$ and $D_{H}=$ $\left\{d_{H}^{1}, d_{H}^{2}, \cdots, d_{H}^{K}\right\}$, where $d_{i}^{k+1}>d_{i}^{k}(i \in\{L, H\}), d_{H}^{1}>d_{L}^{K}$ and $\left|D_{L}\right|=\left|D_{H}\right|=K$. Due to the given hire time set, there may exist some idle time after the last rental contract as the remaining time in the planning horizon is less than the minimum given hire time $d_{L}^{1}$. Let $\kappa$ be the set of the last rental contract for each $h_{k}$ in the planning horizon and the unit inventory cost per time period be $\bar{c}$. For short, let $R\left(d_{i}\left(h_{k}\right)\right)=\theta_{i} d_{i}\left(h_{k}\right)-\frac{1}{2}\left(d_{i}^{2}\left(h_{k}\right)+q^{2}\right)-Y-a q d_{i}\left(h_{k}\right) . d_{i}^{*}=\arg \max _{d_{i} \in D_{i}}\left\{R\left(d_{i}\right)\right\}$ refers to the efficient hire time of type $i$. Thus, the problem degenerates into selecting an optimal hire time from the given hire time set.

We still consider the relaxed problem where $I C_{H L}\left(h_{k}\right)$ and $I R_{L}\left(h_{k}\right)$ are binding constraints.

$$
\begin{gathered}
\Pi\left(D, S\left(\theta_{H}\right)\right)= \\
\max _{\left\{D, S\left(\theta_{H}\right)\right\}} M\left\{\sum_{i \in\{L, H\}} f_{i}\left[R\left(d_{i}\left(h_{0}\right)\right)-S\left(\theta_{H}\right)\right]+\sum_{k=1}^{N} \mathbb{E}_{h_{k}^{z}} \sum_{j \in\{L, H\}} \delta^{t_{j}\left(h_{k}^{z}\right)} f_{z j} R\left(d_{j}\left(h_{k}^{z}\right)\right)\right\} \\
-\bar{c} \sum_{j \in \kappa} \mathbb{E}_{h_{k}}\left(T-t_{j}\left(h_{k}\right)+d_{j}\left(h_{k}\right)\right) \\
\text { s.t. } \quad \begin{array}{c}
I R_{L}\left(h_{k}\right) \\
S\left(\theta_{L} \mid h_{k}\right)=0 \\
t_{j}\left(h_{k}\right)+d_{j}\left(h_{k}\right) \leq T, \quad j \in \kappa \\
\forall \sum_{k} \in \boldsymbol{H}_{k}(0 \leq k \leq N)
\end{array}
\end{gathered}
$$

We use a binary tree (see Figure 1) to illustrate the computation process. Node $t=0$ is the beginning of the binary tree. Nodes with odd numbers represent the low type customers and nodes with even numbers denote the high type customers. Let $l$ be a general node in the tree and $\vartheta(l)$ be the type of that node. If $l \bmod 2=1$, $\vartheta(l)=L$; if $l \bmod 2=0, \vartheta(l)=H$. For short, let $h_{l}$ be the history ended at node $l$ and $t_{l}$ be the beginning time of rental contract at node $l$. The objective function of this problem implies that given the alternative hire time sets, there is a tradeoff between efficient hire discount of current state and future profit maximization. For a node in tree, if the efficient hire time $d_{\vartheta(l)}\left(h_{k}\right)=d_{\vartheta(l)}^{*}$ is selected by the leasing company, then the next rental contracts for both types are available from time $t_{l}+d_{\vartheta(l)}^{*}$; if the hire time of node $l$ is less than the efficient hire time $d_{\vartheta(l)}^{*}$, the next rental contracts start earlier than the former case at the cost of sacrificing 
the profit at the current state. The optimal hire time sequence strikes a balance between current state maximization and expected future profit maximization.

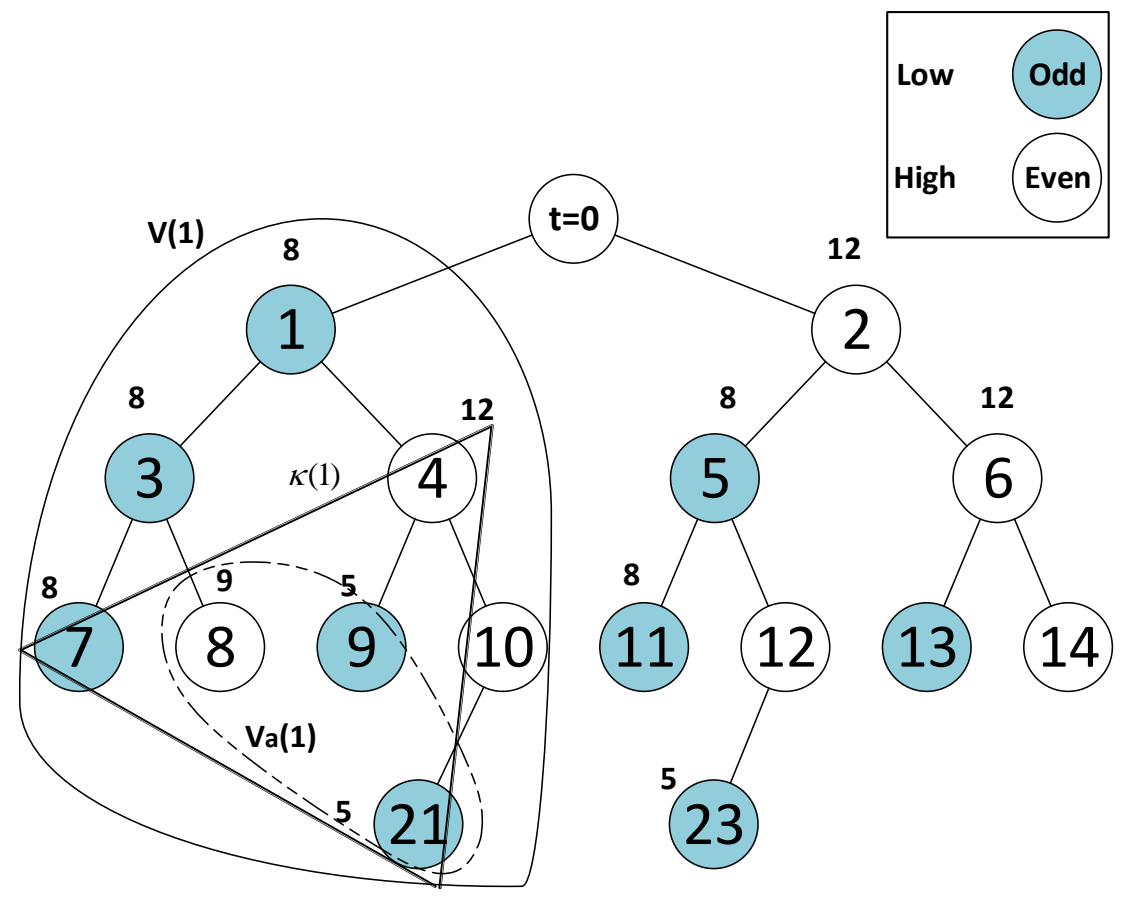

Figure 1. A Binary Tree, $d_{L}^{*}=8, d_{H}^{*}=12$ and $T=25$

The dynamic programming algorithm is designed in the following way. First assign the efficient hire time of both types to the corresponding nodes until the second last contracts of different histories and calculate the hire time of last rental contract for each history subject to the time constraint. For example, in Figure 1 , assign $d_{L}^{*}=8$ for odd nodes and $d_{H}^{*}=12$ for even nodes except the last rental contract. For this feasible solution, let $\kappa(l)$ be the set of last rental contract for each history rooted at node $l$ and $V(l)$ be a subtree rooted at node $l . V(l)$ can be divided into two sets, $V(l)=\left\{V_{a}(l), V_{n}(l)\right\}$, where $V_{a}(l)=\left\{k \mid k \in \kappa(l)\right.$ and $d_{\vartheta(k)}\left(h_{t_{k}}\right) \neq$ $\left.d_{\vartheta(k)}^{*}\right\}$ is the set of nodes in $\kappa(l)$ whose hire time do not equal to the efficient hire time of the corresponding types and $V_{n}(l)=V(l) \backslash V_{a}(l)$ is the set of rest nodes in $V(l)$ whose hire time equal to the efficient hire time of the corresponding types. Next, for each node with efficient hire time, adjust this feasible solution by decreasing node $l$ by $\eta$ and increasing nodes $j$ in $V_{a}(l)$ by $\eta$. Let $\Delta_{l}(\eta)$ be the net change of the expected profit which includes the changes of expected profit of hire time at nodes $l$ and $j \in V_{a}(l)$, the changes of the expected profit for nodes $j \in V_{n}(l)$ whose hire time remain the same, the changes of inventory cost of nodes 
in $\kappa(l)$ and the possible change of $S\left(\theta_{H}\right)$.

$$
\begin{aligned}
\Delta_{l}(\eta)= & f\left(h_{l}\right) \delta^{t_{l}}\left[R\left(d_{\vartheta(l)}\left(h_{l}\right)-\eta\right)-R\left(d_{\vartheta(l)}\left(h_{l}\right)\right)\right]+\sum_{j \in V_{n}(l)} f\left(h_{j}\right) \delta^{t_{j}} R\left(d_{\vartheta(j)}\left(h_{j}\right)\right)\left(\delta^{-\eta}-1\right) \\
& +\sum_{j \in V_{a}(l)} f\left(h_{j}\right)\left[R\left(d_{\vartheta(j)}\left(h_{j}\right)+\eta\right) \delta^{t_{j}-\eta}-R\left(d_{\vartheta(j)}\left(h_{j}\right)\right) \delta^{t_{j}}\right] \\
& +\bar{c} \sum_{k \in \kappa(l) \backslash V_{a}(l)} f\left(h_{k}\right) \delta^{t_{k}}\left(T-t_{k}-d_{\vartheta(k)}\left(h_{k}\right)+\eta\right)-f_{H} \triangle \theta \triangle_{l}\left(S\left(\theta_{H}\right)\right)
\end{aligned}
$$

where $\triangle_{l}\left(S\left(\theta_{H}\right)\right)=\mathbf{1}\left(l \in h_{k}^{\hat{L}}\right)\left[-\eta \triangle f^{k} \delta^{t_{l}}+\sum_{j=k+1}^{N} \triangle f^{j} \delta^{t_{L}\left(h_{j}^{\hat{L}}\right)} d_{L}\left(h_{j}^{\hat{L}}\right)\left(\delta^{-\eta}-1\right)+\right.$ $\left.\mathbf{1}\left(h_{j}^{\hat{L}} \cap V_{a}(l)\right) \eta \triangle f^{N} \delta^{t_{L}\left(h_{j}^{\hat{L}}\right)-\eta}\right]$.

Compute $\Delta_{l}\left(\eta_{\min }\right)$ where $\eta_{l \text { min }}=\min _{k \in\{2, \cdots, K\}}\left\{d_{\vartheta(l)}^{k}-d_{\vartheta(l)}^{k-1}\right\}$ and $\Delta\left(\eta_{l \text { max }}\right)$ where $\eta_{l \max }=\min \left\{d_{\vartheta(l)}^{*}-d_{\vartheta(l)}^{1}, \min _{j \in V_{a}(l)}\left\{d_{\vartheta(j)}^{*}-d_{\vartheta(j)}\left(h_{t_{j}}\right)\right\}\right\} . \eta_{l}^{*}=\arg \max \left\{\Delta_{l}(\eta) \mid \Delta_{l}(\eta)>\right.$ $0\}$. If $\eta_{l}^{*}$ is not empty set, then adjust the feasible solution, otherwise continue to next node. Subtrees $V(l)$ rooted at the same level can be calculated separately since the above adjustment does not affect the solution of other subtrees with the same level, e.g., $V(1)$ and $V(2)$. Apply the adjustment repeatedly until $\eta_{l}^{*}$ is an empty set for each node in $V(l) \backslash \kappa(l)$.

Numerical Example 1. Consider an intertemporal nonlinear pricing problem in the planning horizon $T=25$ with different time discount factors $\delta=$ $0.95,0.85,0.65$. There are $M=10$ customers with same hire quantity preference $q=5$. The high type customer with valuation $\bar{\theta}_{H}=3.6$ arrives at the system with probability $f_{H}=0.6$ at time 0 and with consistent probability $f_{H H}=0.6$ during the rest of planning horizon. The low type customer with valuation $\bar{\theta}_{L}=2.6$ enters the system with inconsistent probability $f_{L H}=0.45$. The alternative hire time sets for both types are $D_{L}=[5,6,7,8]$ and $D_{H}=[9,10,11,12]$. Contract setup cost $Y$ is 4 , the unit inventory cost $\bar{c}$ is 0.5 and the unit operating cost $a$ is 0.6. The optimal hire time sequence is shown in Figure 2.

Numerical Example 2. In this example, the valuations of both two types become $\bar{\theta}_{H}=2.8$ and $\bar{\theta}_{L}=2$. The other parameters remain the same. The optimal hire time sequence is illustrated in Figure 3.

Two interesting points can be drawn from these two examples. The first one is that when $\delta$ decreases, the optimal hire time sequence converges to the efficient hire time (The efficient hire time for both types are $d_{H}^{*}=12, d_{L}^{*}=8$ in Example 1 and $d_{H}^{*}=11, d_{L}^{*}=7$ in Example 2). The lessening time discount factor reduces the proportion of future profit in the total expected profit which results in the dominant effect of current profit maximization in the tradeoff. As the time 


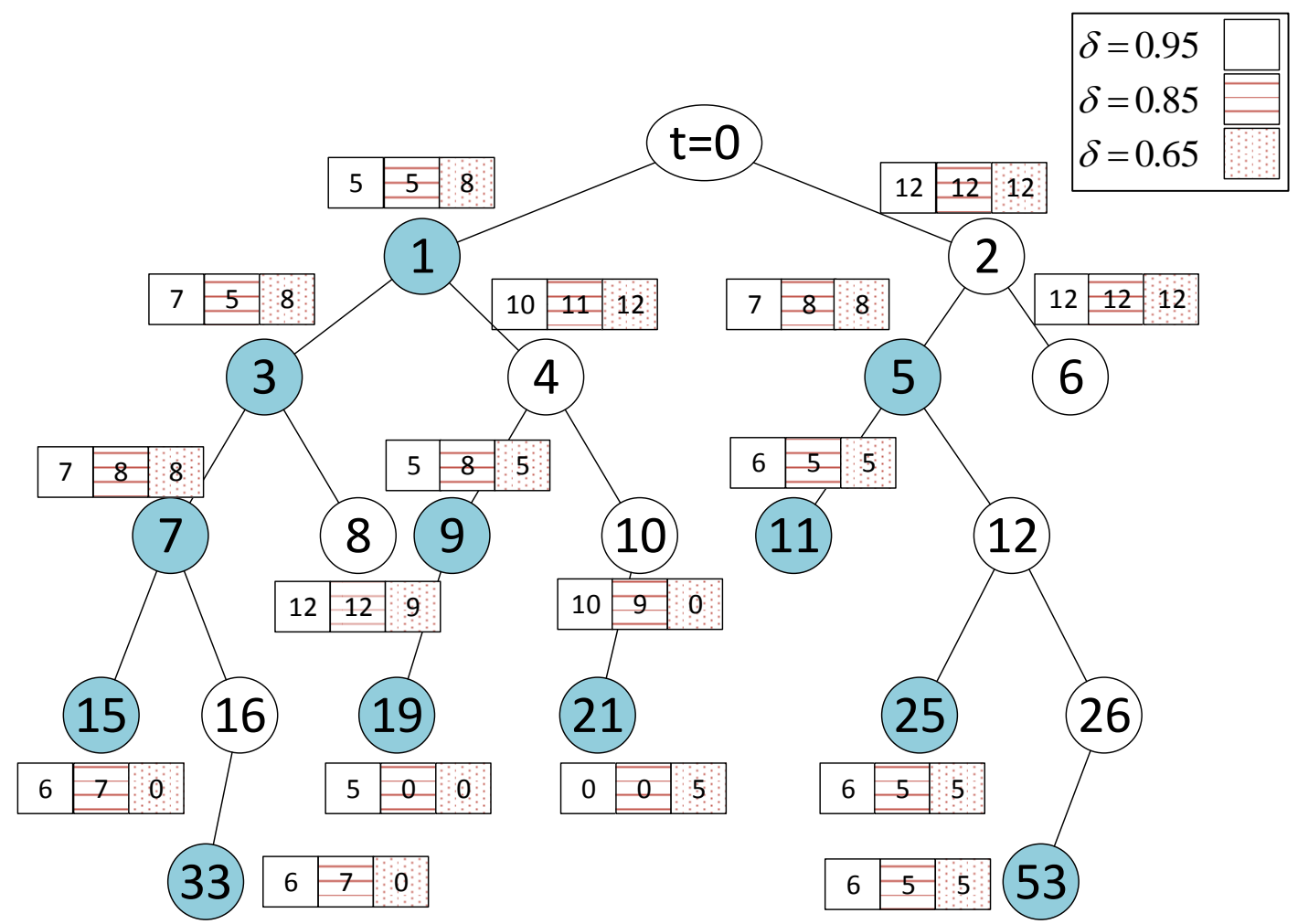

Figure 2. The Optimal Hire Time Sequence of Example 1, $\bar{\theta}_{H}=3.6$ and $\bar{\theta}_{L}=2.6$

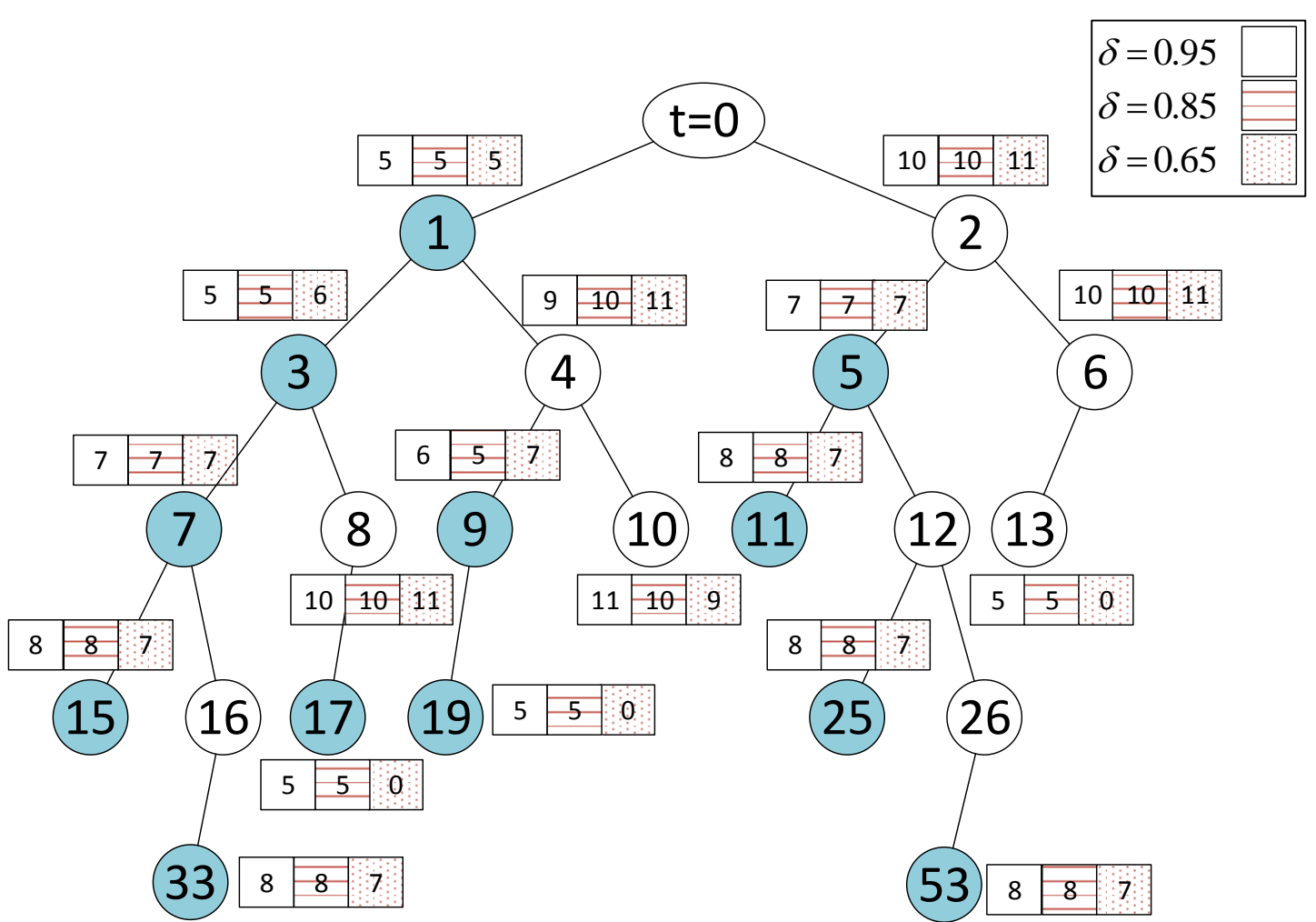

Figure 3. The Optimal Hire Time Sequence of Example $2, \bar{\theta}_{H}=2.8$ and $\bar{\theta}_{L}=2$ 
discount factor diminishes, it is optimal for the leasing company to lease the containers at the efficient hire time in order to maximize the expected profit. In the two examples, when $\delta$ falls from from 0.95 to 0.65 , the optimal hire time sequence except the last rental contract has the trend of converging to the efficient hire time.

Another finding is that the decrement of customer valuations lessens the effect of current profit maximization. In Example 1, $\left(\bar{\theta}_{i}-a\right) q\left(\theta_{H}=15, \theta_{L}=10\right)$ is greater than the maximal alternative hire time $d_{i}^{K}\left(d_{H}^{K}=12, d_{L}^{K}=8\right)$; in Example $2, d_{i}^{1}<\left(\bar{\theta}_{i}-a\right) q<d_{i}^{K}$. The decreasing customer valuation leads to the reducing efficient hire time. Thus, the opportunity cost of leasing the containers at the efficient hire time reduces, which weakens the effect of efficient hire discount. The effect of future profit maximization becomes dominant in the trade-off. This is the reason that even $\delta=0.65$, the optimal hire time of nodes 1 and 3 in Example 2 are 5 and 6 which are less than the efficient hire time of low type, $d_{L}^{*}=7$. In a word, $\left(\bar{\theta}_{i}-a\right) q$ is the main factor of deciding the effect of current state maximization and $\delta$ is the major determinant of the effect of future profit maximization.

\subsubsection{Different hire quantity preferences $\left(\bar{q}_{H}>\bar{q}_{L}\right)$}

We further investigate the case that customers have different hire quantity preferences, $\bar{q}_{H}>\bar{q}_{L}$. In the previous section, because of the same hire quantity preference, there is no container left except the last rental contract in the planning horizon, whereas the varied hire quantity preferences in this section give rise to the phenomenon that after each rental contract, there may be several excess/inadequate units of container. Suppose that the consistent type customers have the priority of satisfying the demand and the inconsistent low type customers (the low type customer of last time changes to the high type customer) are patient and can wait until when idle containers are available. If $h_{k}^{z}=h_{k}^{H}, M f\left(h_{k}^{z}\right) \bar{q}_{H}$ units of container are returned at $t_{i}\left(h_{k}^{z}\right)(i \in\{L, H\})$. The total number of requested containers by both types is $M f\left(h_{k}^{z}\right)\left(f_{H H} \bar{q}_{H}+f_{H L} \bar{q}_{L}\right)$ which is strictly less than the units of available container $M f\left(h_{k}^{z}\right) \bar{q}_{H}$. It implies that $M f\left(h_{k}^{z}\right) f_{H L}\left(\bar{q}_{H}-\bar{q}_{L}\right)$

units of container are left in the company; if $h_{k}^{z} \in\left\{h_{k}^{\hat{L}}, h_{k}^{L}\right\}, M f\left(h_{k}^{z}\right) \bar{q}_{L}$ units of container are returned at time $t_{i}\left(h_{k}^{z}\right)(i \in\{L, H\})$. The consistent low type customer requires $\operatorname{Mf}\left(h_{k}^{z}\right) f_{L L} \bar{q}_{L}$, which is less than $M f\left(h_{k}^{z}\right) \bar{q}_{L}$. But the inconsistent low type customer requests $M f\left(h_{k}^{z}\right) f_{L H} \bar{q}_{H}$ which is greater than the rest of container, $M f\left(h_{k}^{z}\right) f_{L H} \bar{q}_{L}$. Assume that the waiting cost per time is $w . x_{i}\left(h_{k}\right)$ 
represents the inventory level of containers for customer type $i$ after history $h_{k}$. Let $R\left(d_{i}\left(h_{k}\right)\right)=\theta_{i} d_{i}\left(h_{k}\right)-\frac{1}{2}\left(\left(d_{i}^{2}\left(h_{k}\right)+\bar{q}_{i}^{2}\right)-Y-a \bar{q}_{i} d_{i}\left(h_{k}\right)\right.$. The corresponding relaxed optimization problem can be formulated as

$$
\begin{aligned}
& \Pi\left(D, S\left(\theta_{H}\right)\right)=\max _{\left\{D, S\left(\theta_{H}\right)\right\}} M \sum_{i} f_{i}\left[R\left(d_{i}\left(h_{0}\right)\right)-S\left(\theta_{i}\right)\right]+M \sum_{k=1}^{N} \mathbb{E}_{h_{k}^{z}} \sum_{j} \delta^{t_{j}\left(h_{k}^{z}\right)} f_{z j} R\left(d_{j}\left(h_{k}\right)\right) \\
& -\bar{c} \mathbb{E}_{h_{k}}\left(x_{i}\left(h_{k}\right)\right)^{+}-w \mathbb{E}_{h_{k}} \mathbf{1}\left(t_{j}\left(h_{k}\right)-t_{i}\left(h_{k}\right)\right)\left(x_{i}\left(h_{k}\right)\right)^{-} \\
& \text {s.t. } \\
& S\left(\theta_{L} \mid h_{k}\right)=0 \quad I R_{L}\left(h_{k}\right) \\
& S\left(\theta_{H}\right)=\Delta \theta \sum_{k=0}^{N} \delta^{t_{L}\left(h_{k}^{\hat{L}}\right)} \Delta f^{k} d_{L}\left(h_{k}^{\hat{L}}\right) \quad I C_{H L}\left(h_{k}\right) \\
& t_{i}\left(h_{k}\right)+d_{i}\left(h_{k}\right) \leq T \\
& \forall i, j \in\{L, H\}, \forall h_{k} \in \boldsymbol{H}_{k}(0 \leq k \leq N)
\end{aligned}
$$

The objective function in this section is the rental revenue minus inventory cost, operating cost and waiting cost. The other components are the same as the model in the previous section.

The differences between this section and previous section are that (1) subtrees with the same level jointly determine the optimal hire time sequence. For example, the hire time of node 2 affects the available time of idle containers for inconsistent low type customer at node 4; (2) Besides the finite time constraint of the planning horizon, there exist hire quantity constraints for inconsistent low type customer due to different hire quantity preferences, which incurs the inventory cost and waiting cost. While in Section 4.2.1, there is only inventory cost after the last rental contract. The changes of the algorithm are the inclusions of $\Delta_{l}(\eta)$ for nodes $l$ in $V(2)$ and the waiting/inventory cost of each node. The other parts remain the same.

Numerical Example 3. The preferred hire time for both types are $\bar{q}_{H}=10$ and $\bar{q}_{L}=5$. The waiting cost per time $w$ is 1 . The other parameters are the same as in Example 1. The optimal hire time sequence is shown in Figure 4. The number in triangle denotes the preferred hire quantity requested by customers, $M f\left(h_{k}^{z}\right) f_{z i} \bar{q}_{i}(z, i \in\{L, H\})$.

Compared the result in Example 3 with the result in Example 1, one implication for high type customers is that the optimal hire time are the efficient hire time, $d_{H}^{*}=12$ and are insensitive to the variation of time discount factor. This is because the preferred hire quantity of high type in this example is $\bar{q}_{H}=10$, the profit from high type customer becomes larger than that in Example 1. The effect 


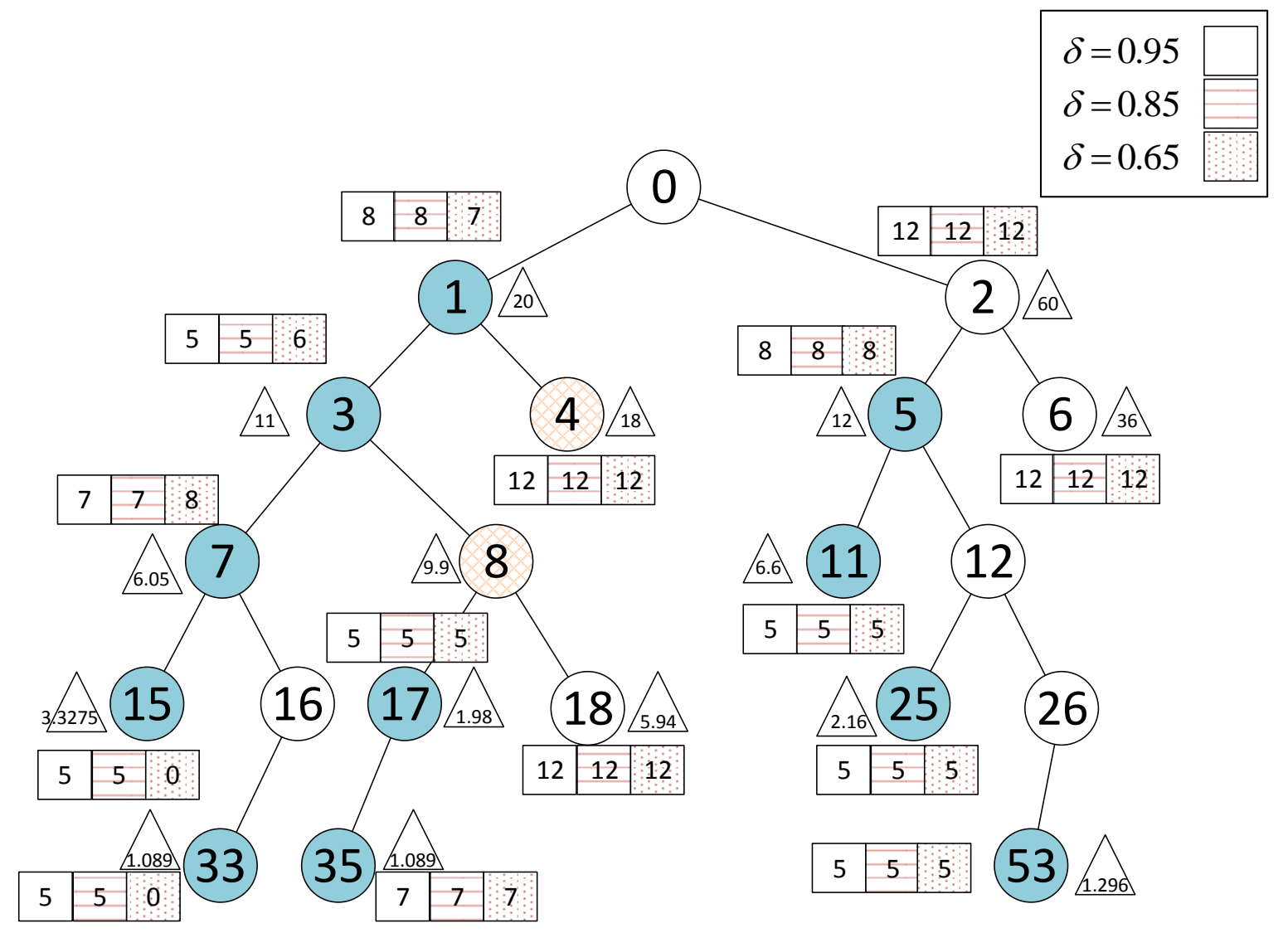

Figure 4. The Optimal Hire Time Sequence of Example 3, $\bar{q}_{H}=10$ and $\bar{q}_{L}=5$

of efficient hire discount (current state profit maximization) dominates the effect of future profit maximization. In addition, considering different hire quantity preferences, there is inventory left for high type customers. Thus, it is optimal for the leasing company to lease containers for high type customers at the efficient hire time. The second implication is that the optimal hire time of low type customers at node 1 is longer than that in Example 1, while the result at node 3 has the opposite trend. The most likely explanation is as follows. Nodes 4 and 8 are inconsistent low type customers. In the optimal solution, customers at node 4 wait until customers at node 2 return containers. The waiting cost of node 4 depends on the difference between the hire time of node 2 and 1 . Then it is reasonable to increase the hire time of node 1 in order to reduce the waiting cost. But customers at node 8 are refused by the leasing company due to long waiting time and the finite horizon time constraint. For node 2, there are 12 units excess inventory. Among them, 9 units is used to satisfy the demand of node 4 and 2.97 units is used to meet the demand of node 18. The hire time of node 3 affects the inventory cost of 2.97 units, thus the optimal hire time of node 3 is less than the efficient 
hire time so as to minimize the time lag between node 2 and node 3 and reduce the inventory cost.

\section{Conclusion}

In this paper, we explore the monopolist's nonlinear pricing problems in static and dynamic environments in the context of container leasing industry. In a static environment, we obtain the closed-form solutions for the capacity-constrained nonlinear pricing problems under different customer groups with multiple types. In a dynamic environment, we concentrate on two customer types in each group. The optimal closed-form solutions are derived for customers with hire time preference. The capacity constraint has distinct effects when customers have same or different hire time preference(s). For customers with preferred hire quantity, on the given alternative hire time sets, we use dynamic programming approach to obtain the numerical optimal solution.

To simplify the analysis, this study has made several assumptions, for example only two customer types are considered in a dynamic environment, hire time and quantity are not determined jointly, and total capacity is fixed. The future work could extend the nonlinear pricing problem from the following perspectives: (1) multidimensional screening problem under both static and dynamic environments, that is, the monopolist decides optimal hire time and quantity simultaneously; (2) include the competition effect into the model; (3) consider the capacity expansion in the planning horizon; (4) analyze the model with finitely many customer types.

\section{References}

Anderson, E. T. and J. D. Dana Jr (2009). When is price discrimination profitable? Management Science 55(6), 980-989.

Armstrong, M. (1996). Multiproduct nonlinear pricing. Econometrica, 51-75.

Athey, S. and I. Segal (2013). An efficient dynamic mechanism. Econometrica $81(6), 2463-2485$.

Battaglini, M. (2005). Long-term contracting with markovian consumers. American Economic Review, 637-658. 
Battaglini, M. and R. Lamba (2014). Optimal dynamic contracting: the first-order approach and beyond. Unpublished manuscript, Princeton University.

Bell, M. G., X. Liu, J. Rioult, and P. Angeloudis (2013). A cost-based maritime container assignment model. Transportation Research Part B: Methodological 58, 58-70.

Bergemann, D. and M. Said (2011). Dynamic auctions. Wiley Encyclopedia of Operations Research and Management Science.

Cheung, R. K. and C.-Y. Chen (1998). A two-stage stochastic network model and solution methods for the dynamic empty container allocation problem. Transportation science 32(2), 142-162.

Dobbs, I. M. (1995). Hiring and leasing with nonlinear prices. Management Science 41(11), 1793-1805.

Drewry (2014). Container leasing industry 2014/15, Technical Report.

Gans, N. and S. Savin (2007). Pricing and capacity rationing for rentals with uncertain durations. Management Science 53(3), 390-407.

Huang, G. Q. and S. X. Xu (2013). Truthful multi-unit transportation procurement auctions for logistics e-marketplaces. Transportation Research Part B: Methodological 47, 127-148.

Kakade, S. M., I. Lobel, and H. Nazerzadeh (2013). Optimal dynamic mechanism design and the virtual-pivot mechanism. Operations Research 61(4), 837-854.

Maskin, E. and J. Riley (1984). Monopoly with incomplete information. The RAND Journal of Economics 15(2), 171-196.

Mussa, M. and S. Rosen (1978). Monopoly and product quality. Journal of Economic Theory 18(2), 301-317.

Myerson, R. B. (1981). Optimal auction design. Mathematics of Operations Research 6(1), 58-73.

Pai, M. M. and R. Vohra (2013). Optimal dynamic auctions and simple index rules. Mathematics of Operations Research 38(4), 682-697. 
Papier, F. and U. Thonemann (2010). Capacity rationing in stochastic rental systems with advance demand information. Operations Research 58(2), 274288.

Pavan, A., I. Segal, and J. Toikka (2014). Dynamic mechanism design: A myersonian approach. Econometrica 82(2), 601-653.

Rochet, J.-C. and L. A. Stole (2003). The economics of multidimensional screening. Econometric Society Monographs 35, 150-197.

Savin, S. V., M. A. Cohen, N. Gans, and Z. Katalan (2005). Capacity management in rental businesses with two customer bases. Operations Research 53(4), 617631.

Shu, J. and M. Song (2013). Dynamic container deployment: two-stage robust model, complexity, and computational results. INFORMS Journal on Computing 26(1), 135-149.

Song, D.-P. and J.-X. Dong (2012). Cargo routing and empty container repositioning in multiple shipping service routes. Transportation Research Part B: Methodological 46(10), 1556-1575.

Sundararajan, A. (2004). Nonlinear pricing of information goods. Management Science 50(12), 1660-1673.

Textainer (2014). Textainer group holdings limited 2014 annual report.

Theofanis, S. and M. Boile (2009). Empty marine container logistics: facts, issues and management strategies. GeoJournal 74(1), 51-65.

UNCTAD (2014). Review of maritime transport 2014, Technical Report. United Nations Council on Trade and Development.

Wilson, R. B. (1993). Nonlinear pricing. Oxford University Press.

Zou, B., N. Kafle, O. Wolfson, and J. J. Lin (2015). A mechanism design based approach to solving parking slot assignment in the information era. Transportation Research Part B: Methodological 81, 631-653. 